\title{
El Pomerium invisible. A PROPÓsito de las CARACTERÍSTICAS ARQUITECTÓNICAS DE LOS RECINTOS amurallados de la COLONIA ROMULA HisPaLIS
}

Daniel JimÉnez Maqueda

PEDRo PÉREZ Quesada

Consejería de Educación y Consejería de Cultura de la Junta de Andalucía

\section{RESUMEN}

El presente artículo tiene como objetivo la reconstrucción de las características arquitectónicas de los recintos amurallados de la Colonia Romula Hispalis. No obstante, como quiera que nunca se ha documentado de forma inequívoca un lienzo de aquellos, hemos denominado este artículo "El pomerium invisible". En este sentido, se defiende la existencia de al menos dos recintos amurallados. El primero sería contemporáneo de la concesión por César del estatuto colonial a Hispalis, en el 45 a.C., o de la segunda deducción de colonos por parte de Augusto, hacia el 15-13 a.C. El segundo sería erigido durante el siglo II d.C., consecuencia del espectacular auge que experimentó la ciudad con los Antoninos.

\section{Palabras Clave}

Hispalis, Pomerium, Murallas.

\section{ABSTRAC}

This article is intended to rebuild the architectural features of Colonia Romula Hispalis' walls. Since they have never been documented, so it will be called 'The invisible pomerium'. In this respect, it is upheld the existence of a least two walls, the first one would have been erected when Hispalis was granted the colonial status by Caesar in $45 \mathrm{BC}$, or with the second deduction of settlers by August in 15-13 BC. On the other hand, the second wall would have been erected in the $2^{\text {nd }}$ century, as a result of the big importance of the city with the Antonines. 
1. Entorno a los FRagmentos de LAS MURALlas DE HISPALIS

En el siguiente epígrafe efectuamos una relación de todos los restos que la historiografía sevillana y la arqueología han vinculado con el recinto amurallado de la Colonia Romula Hispalis (figura 1). El conocimiento de la mayoría de ellos se debe a hallazgos casuales, consecuencia de la realización de obras de infraestructura en el siglo pasado, o a noticias extraídas de bibliotecas y archivos ${ }^{1}$. Los proporcionados por las intervenciones arqueológicas, salvo las de la Encarnación y el Patio de Banderas del Alcázar, muestran una marcada indefinición cronológica y/o las descripciones que ofrecen sus excavadores no permiten identificarlos de forma inequívoca con los recintos amurallados de Hispalis. Por ello no conocemos ni su cronología ni sus características constructivas (Jiménez Martín, 2002, 474-475; González Acuña, 2005, 82; Beltrán Fortés et alii, 2005, 69).

\subsection{Parroquia de SANTA Catalina.}

Cuando en 1721 se procedió a la apertura de los cimientos de la capilla del Rosario y del Sagrario de la Parroquia de Santa Catalina, se detectaron los restos de un muro de piedra labrada de más de 3 varas de grueso (2'50 m). Estos discurrían en dirección a la Plazuela de la Paja, denominación que se corresponde con la actual Ponce de León (Collantes de Terán, 1977, 73).

\subsection{MERCADO DE LA ENCARNACIÓN.}

En el transcurso de la vigilancia de movimientos de tierra efectuados en la $\mathrm{V}$ fase de intervención arqueológica en el Mercado de la Encarnación, se documentó una estructura identificada por sus excavadores con un fragmento de muralla en virtud de sus características morfológicas, constructivas y orientación. Dichas características consisten en una

$1 \mathrm{El}$ presente artículo constituye la adaptación de un capítulo de la tesis doctoral de uno de nosotros. Con el título Sevilla amurallada. Ensayo de reconstrucción del trazado y las características arquitectónicas de los recintos defensivos de la Colonia Iulia Romula Hispalis y madīnat Išbīlia (siglo I a.C.-siglo XIII), fue defendida el día 23 de marzo de 2012 en el Departamento de Prehistoria y Arqueología de la Facultad de Geografía e Historia de la Universidad de Sevilla. Bajo la dirección de don Fernando Amores Carredano y de don Miguel Ángel Tabales Rodríguez, obtuvo la calificación de sobresaliente por el tribunal compuesto por don Julio Navarro Palazón, don Rafael Valencia Rodríguez, don Alfonso Jiménez Martín, don Alberto León Muñoz y don Pedro Mateos Cruz. estructura erigida con sillares de piedra alcoriza dispuestos en opus quadratum, unas dimensiones de $6 \mathrm{~m}$ de longitud por $4 \mathrm{~m}$ de anchura y orientación en diagonal. Estas características permitieron a sus excavadores plantear que se tratara de una esquina de la cerca o una de las torres de una puerta (figura 2) (González Acuña, 2005, 82-83; 2011, 6162; Amores, 2005, 148; Amores y González Acuña, 2004; 2006a, 206).

Aunque no fue posible determinar el momento en que fue erigida, pues no se llevó a cabo su registro estratigráfico completo, sus excavadores defienden que su inserción dentro de una trama urbana programada permitiría sostener que su erección formó parte del diseño global del sector Se fecharía pues a mediados del siglo I d.C. (Amores y González Acuña, 2006b, 219; González Acuña, 2011, 62).

En cuanto al análisis de este hallazgo, se trata del que a priori tiene mayores posibilidades de pertenecer a la cerca de Hispalis. Sin embargo, los argumentos al respecto no parecen definitivos, a lo que cabría añadir el peligro de formular una propuesta sobre el pomerium de la Colonia Romula en virtud de tan escasa evidencia arqueológica. En esta línea, el cercano caso cordobés alerta sobre lo aventurado que resulta atribuir una única cronología a la totalidad del recinto amurallado en función de la datación de un lienzo concreto. Así, se han documentado lienzos con un amplio marco cronológico, que ponen de manifiesto que la formalización del recinto de la Colonia Patricia no obedeció a un único impulso constructivo.

\subsection{Parroquia de SAN MARTÍN.}

Santiago Montoto observó que la torre del campanario de dicha parroquia se erigía sobre muros más antiguos de 2'70 m de espesor (Montoto, 1981, 109). Juan Campos relacionó este extremo con los restos de la muralla romana (Campos, 1991, 45; 1993, 188).

\subsection{CASA DE Miguel DE MAÑARA.}

En el transcurso de las obras de restauración se localizó, aunque no se documentó en su totalidad por la aparición del freático a 3’10 metros de profundidad, un muro de sillares ciclópeos anterior a las construcciones islámicas. En virtud de su emplazamiento sus excavadores lo relacionaron con la cerca imperial (Ojeda, 1993, 133; 1995, 212; Ojeda y Tabales, 1994, 138). 


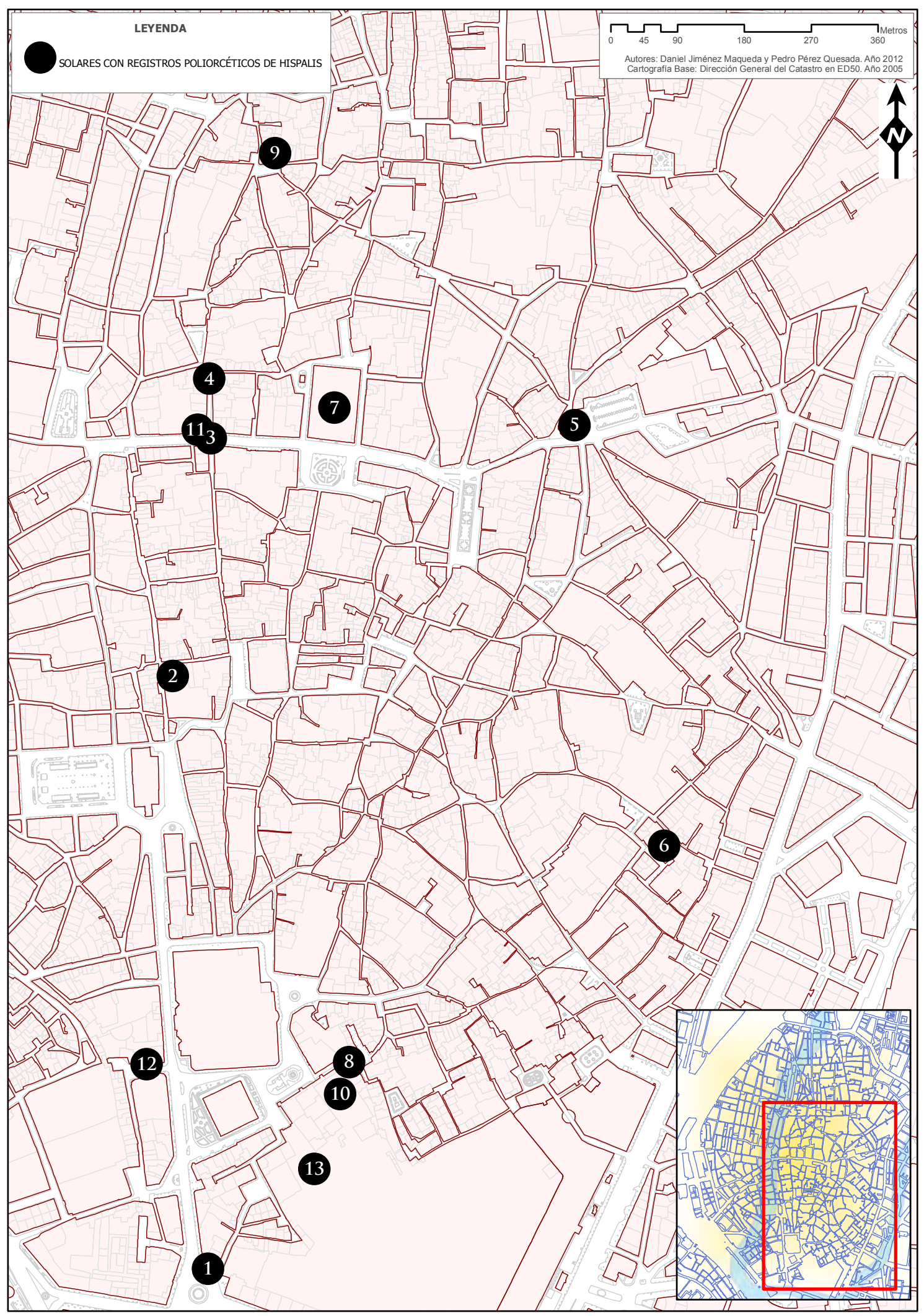

Figura 1. Estructuras que se han vinculado con registros. 


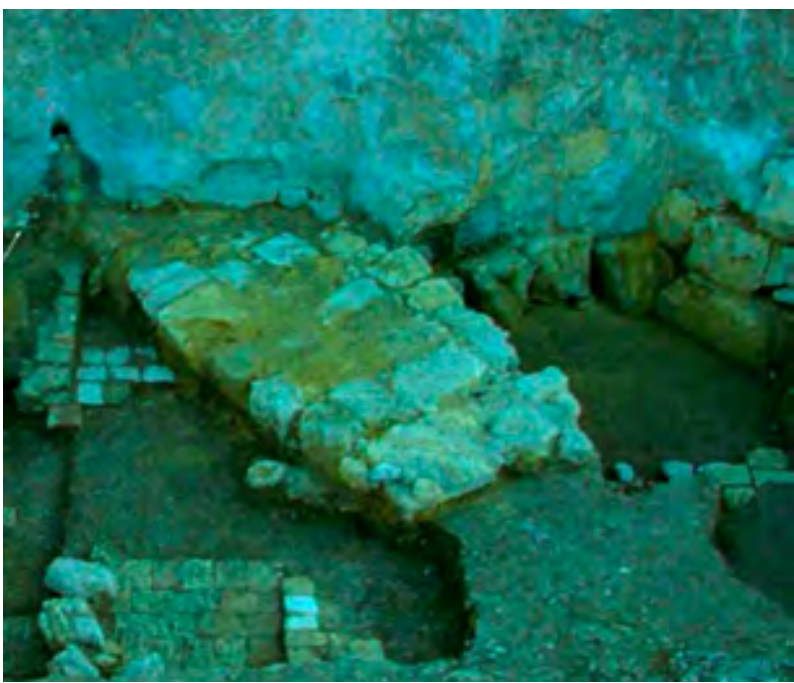

Figura 2. Estructura documentada en la $\mathrm{V}$ fase de intervención en el Mercado de la Encarnación (fotografía cortesía de Fernando Amores).

\subsection{Patio de Banderas del AlCÁzAR N ${ }^{\circ} 16$.}

Durante los trabajos de rehabilitación del inmueble, se documentó con metodología arqueológica una alineación de sillares isódomos, de módulo romano (codo de 0'52) y de piedra alcoriza, con llagas irregulares y cuñas de grava (figura 3 ) (Tabales, 2002a, 205; 2002b, 204-206; 2002c, 153; 2010b, 82-83). Dichas características, de las que puede inferirse el empleo de material de acarreo a base de sillares de módulo romano enripiados, no permiten plantear reflexiones más sólidas en lo que a su cronología se refiere. Así pueden ir desde lo tardoanti-

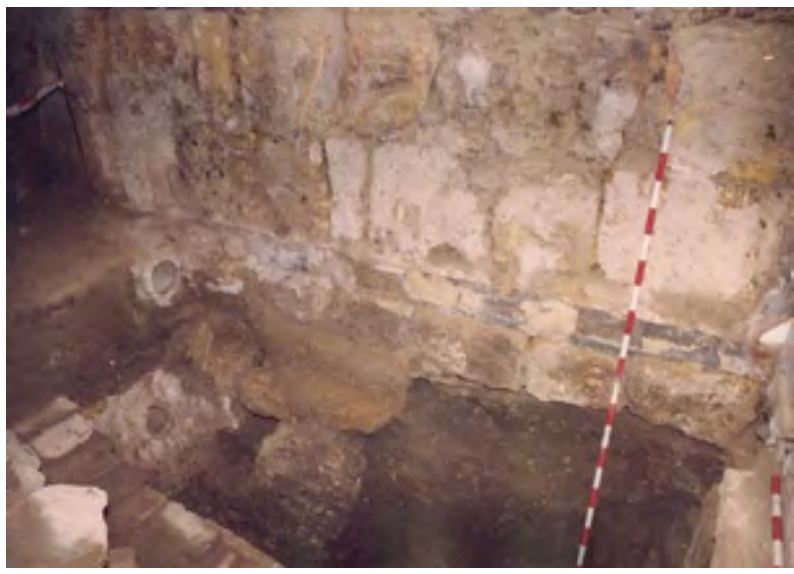

Figura 3. Muro de sillares documentado en el número 16 del Patio de Banderas del Alcázar de Sevilla (fotografía cortesía de Miguel Ángel Tabales). guo (González Acuña, 2011, 63) hasta casi cualquier momento del período omeya.

\subsection{Patio de Banderas del ALCÁZAR.}

En la campaña de 2010 se ha documentado una alineación de sillares con dirección este-oeste, una anchura de 1'20 m, aparejo de opus quadratum de sillares de piedra alcoriza almohadillados, dispuestos en hiladas alternas a soga y tizón, tomados con mortero de barro, cuñas de piedra en las llagas y un emplecton interior a base de mampuestos de pequeñas dimensiones y cerámicas colocados en tongadas horizontales. En su extremo occidental, la coincidencia exacta en la alineación vertical de las diferentes hiladas es interpretada como la jamba de un acceso (figura 4) (Tabales, 2010c, tomo I, 67; Vargas Lorenzo, 2010, tomo II, 19 ss.). Sus excavadores le asignan una cronología comprendida entre el 60 y el 30 a.C., aunque perduraría hasta mediados del siglo $\mathrm{V}$ d.C., y la identifican como la hoja interior de un muro de mayor espesor que formaría parte de las murallas erigidas por César (Tabales, 2010c, tomo I, 88).

\subsection{Portada de la Montería del Alcázar.}

En este punto del Alcázar se documentó con metodología arqueológica una estructura de sillares calizos, trabados mediante argamasa, cuñas de ladrillo, dispuestos sobre un emplecton caementicio, que empleaba ladrillos y cascotes de roca alcoriza como asiento, y cuya cronología no iría más allá del siglo I a.C. (figura 5). Su excavador sugiere que formara parte de una torre o lienzo de muralla

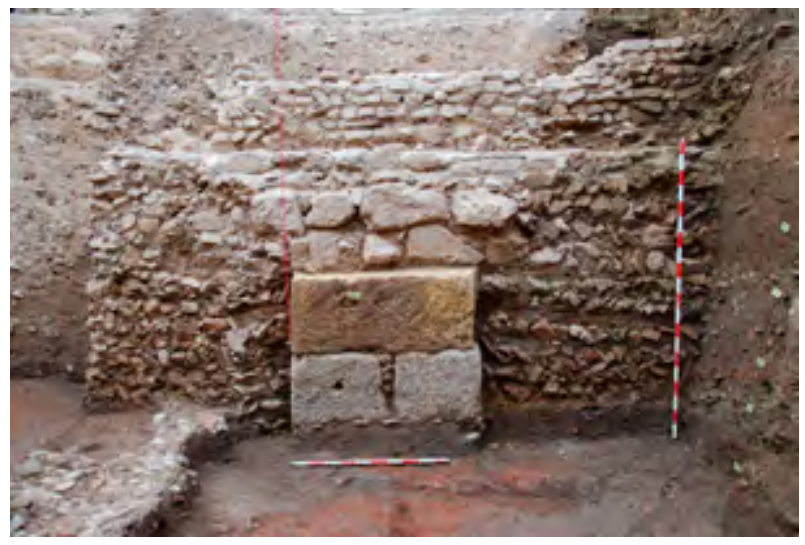

Figura 4. Estructura de sillares documentada en el Patio de Banderas del Alcázar de Sevilla (fotografía cortesía de Miguel Ángel Tabales). 
en función de su técnica constructiva y su emplazamiento en el límite del promontorio original de la ciudad, si bien sin descartar otros usos (Tabales, 2006, 14-15; 2010a, 2721-2722; 2010b, 58-59).

\subsection{Plaza DE VILlasís.}

Al efectuar en 1950 la apertura de la zanja del alcantarillado del Teatro Álvarez Quintero, se localizó en la Plaza de Villasís, a un metro por debajo de la rasante y sin agotar su potencia, pues dicha zanja concluía a $430 \mathrm{~m}$, un muro de sillares de caliza de $3 \mathrm{~m}$ de espesor. Este muro parecía cruzar la plaza desde la calle Cuna hacia la de Orfila (Collantes de Terán, 1977, 75).

\subsection{CALLE ORFILA.}

Cuando en 1952 se levantó el adoquinado para proceder a su pavimentación, se documentó, a muy escasa profundidad, un muro de derretido de $2 \mathrm{~m}$ de espesor y unos $20 \mathrm{~m}$ de longitud. Este discurría por el centro de la calle y practicaba frente a la capilla de San Andrés un pequeño quiebro hacia la calle Daoíz (figura 6) (Collantes de Terán, 1977, 75) Una reciente vigilancia de obras ha descartado que se tratara de un lienzo del recinto amurallado de Hispalis, pues su técnica constructiva es el tapial (figura 7) (Oliva, 2008).

\subsection{CALLE MARTÍN VILLA.}

En 1950 se localizó, a unos $80 \mathrm{~m}$ de los restos documentados en la Plaza de Villasís y frente a los números 7 y 8 , un muro transversal al eje de la calle. Con un espesor de 1'95 m estaba erigido a base

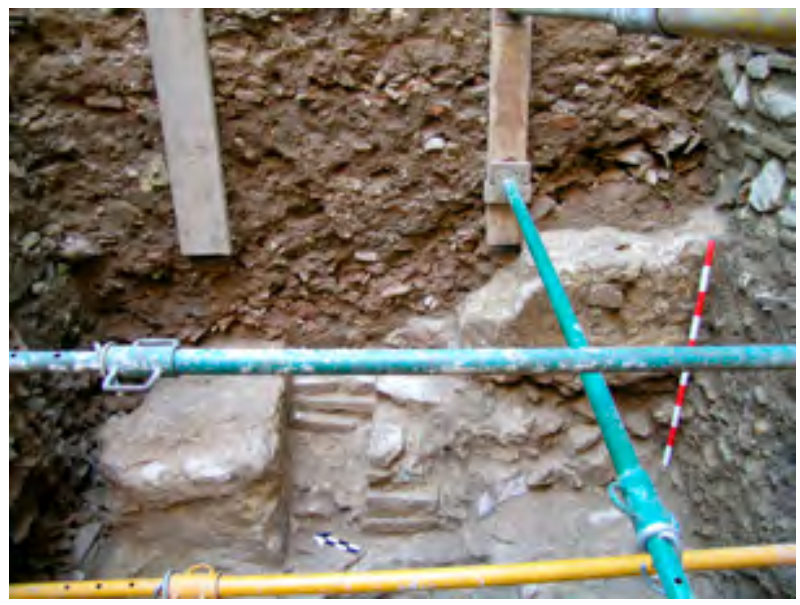

Figura 5. Estructuras de sillares documenta en la Portada de la Montería del Alcázar de Sevilla (fotografía cortesía de Miguel Ángel Tabales).

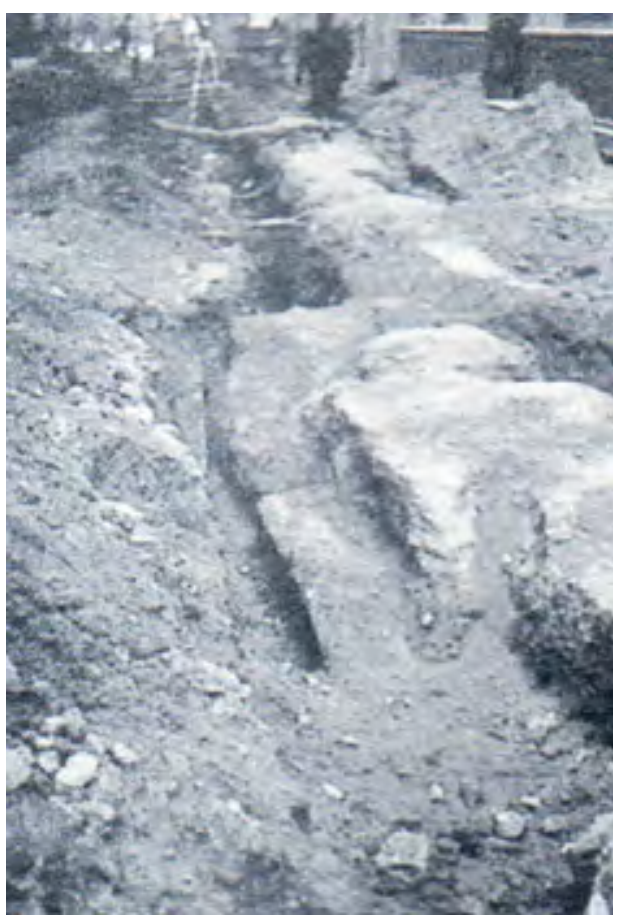

Figura 6. Estructura localizada en la calle Orfila en el transcurso de obras de pavimentación llevadas a cabo en 1952 (Collantes de Terán, 1977).

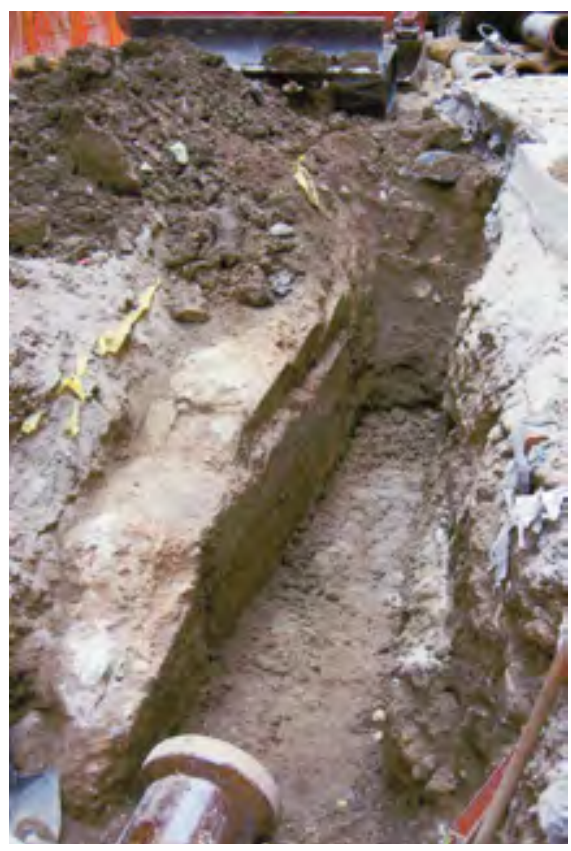

Figura 7. Estructura documentada en la calle Orfila en el transcurso de obras de saneamiento llevadas a cabo en 2008 (fotografía cortesía de Pablo Oliva). 
de paramentos de piedra con un relleno de piedra y argamasa (Collantes de Terán, 1977, 75).

\subsection{CALLE GALLEGOS.}

Juan Campos se hizo eco de un documento, localizado en el Archivo de la Comisión de Monumentos, en el que se alude al hallazgo de muros de sillares de gran espesor, uno de ellos identificado con el dado del espigón de una puerta (Campos, 1991, 46).

\subsection{Plaza del CABILDO.}

Ramón Corzo publicó una fotografía en la que se observa cómo al excavar los cimientos del edificio Plaza del Cabildo, junto al Postigo del Aceite, se localizó una estructura de opus caementicium, paralela a la línea de fachada de aquel e identificada con los restos de la cerca romana (figura 8) (Corzo, 1997, 211). Sin embargo, por su emplazamiento debe corresponder con los recintos almohades del Alcázar (Ordóñez, 2003, 68-69; González Acuña, 2011, 419).

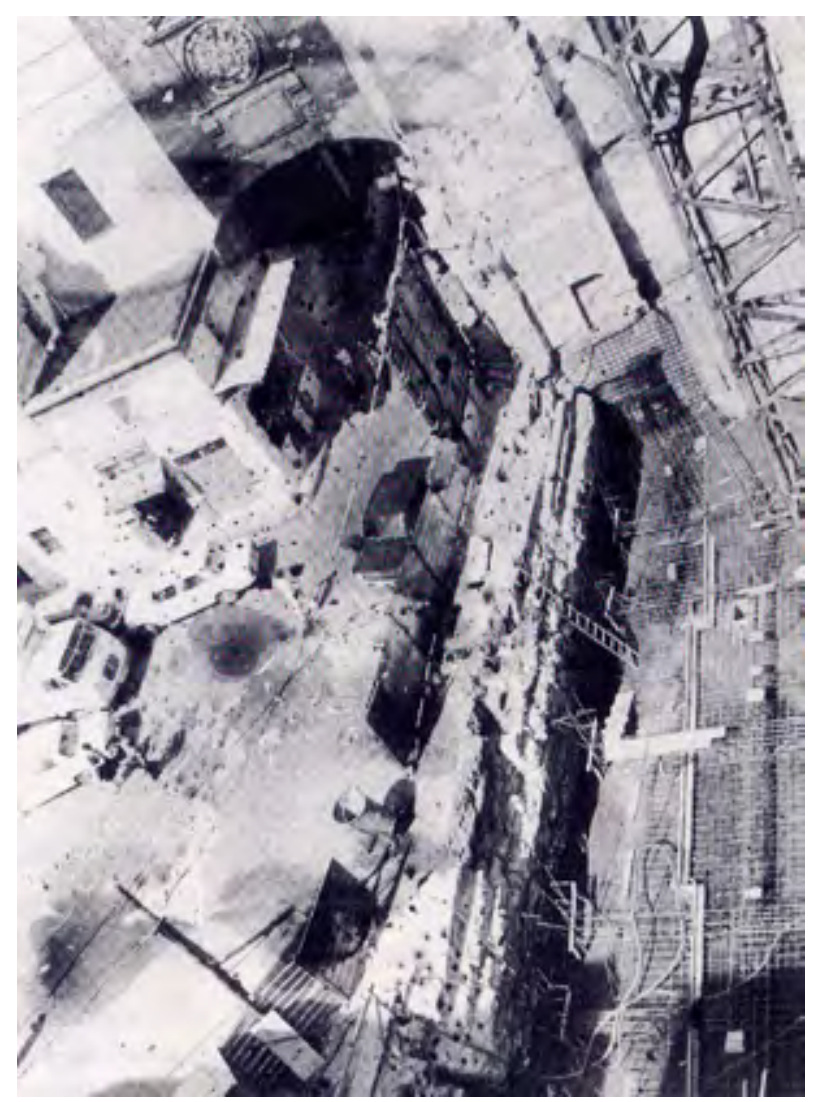

Figura 8. Muralla romana en el sector del Postigo del Aceite de Sevilla según Corzo (1997).

\subsection{Avenida de LA CONSTITUCIÓN.}

En el escueto resumen que Carriazo publicó sobre su inspección de la zanja que en 1960 se excavó para el alcantarillado desde la Puerta de Jerez a la Plaza de San Francisco, se hace alusión al hallazgo de la muralla romana frente a la puerta principal de Zahara, "correspondiendo al estrangulamiento de la calle San Gregorio, donde estuvo una puerta”. Dicha muralla habría estado paramentada de sillería, aunque tan sólo se documentó el mortero del interior, y junto a ella se localizó una sepultura de inhumación con cubierta de tegulae (Carriazo, 1974-1975, 92-93). Sin embargo, hay quien ha sugerido que se trata de estructuras de carácter portuario, tales como malecones (Ordóñez, 1998, 157-159).

\section{Reconstruyendo las murallas de Hispalis.}

Del análisis de los restos que la historiografía atribuye a la cerca de la Colonia Romula sólo se pueden hacer algunas sugerencias en relación a la fecha de su erección. Para ello nos basamos tanto en el contexto histórico como en las características arquitectónicas.

\subsection{EL CONTEXTO HISTÓRICO DE LAS MURALLAS} DE HISPALIS.

Si se tiene en cuenta el contexto histórico, tres habrían sido los períodos en los que fue necesaria la erección de fortificaciones en Hispania durante el dominio romano (Hauschild, 1994).

Las fortificaciones de entidad dejaron de ser necesarias cuando finalizó la conquista y la pacificación de la Península. Las murallas erigidas a partir de este momento no se concibieron para hacer frente a ataques militares sino tan sólo para delimitar el pomerium, con un marcado carácter simbólico (Gros, 1992; Hauschild, 1994).

Durante la segunda mitad del siglo II d.C., justificarían la erección de nuevas construcciones defensivas las incursiones de los mauri procedentes del Norte de África (García y Bellido, 1955; Gozalbes, 1979; Santos, 1980). El hecho de que los ataques tuvieran un ámbito de afección limitado en el tiempo $\mathrm{y}$ en el espacio explica que los ejemplos sean muy escasos (Hauschild, 1994).

Desde fines del siglo III d.C. hasta finales del IV, las ciudades hispanas se vieron obligadas a construir nuevas fortificaciones para hacer frente a las incursiones de las tribus germánicas (Hauschild, 1994; Fernández Ochoa y Morillo, 1991; 1992; 2002). 
Esta cronología se atribuyó a la muralla detectada en Italica en las prospecciones arqueológicas de los años 90 (Rodríguez Hidalgo, 1997, 108; Rodríguez Hidalgo et alii, 1999, 79, 81 y 94; Caballos et alii, 1999, 62). Del mismo modo, esta datación se sostuvo en un principio para la estructura documentada en la Encarnación (Amores, 2005, 148; Amores y González Acuña, 2006a, 206).

En relación a las murallas sevillanas se puede afirmar que se erigieron al final del primero de los períodos mencionados, a lo largo de la segunda mitad del siglo I a.C. Serían consecuencia de la concesión del estatuto colonial a Hispalis por César, en el 45 a.C., o contemporáneas de la adscripción por Augusto de nuevos colonos (adscriptio nouorum colonorum), hacia el 15-13 a.C. (Ordóñez, 1998, 64$68 ; 2002,14 ; 2005,110)$.

En este sentido, pese a que en líneas generales existe un evidente hilo conductor entre la política colonial de César y la de Augusto, son también manifiestas las diferencias entre ambas. En contraste con la política de César, quien en parte procedió a la creación de las denominadas colonias titulares, es decir sin que tuviese lugar deductio alguna, la de Octavio tuvo un carácter fundamentalmente militar, consistente en el asentamiento de veteranos (González Román, 1991, 98-100). De este modo, en función del número de individuos participantes en la fundación colonial, se pueden inferir las necesidades de espacio para los mismos. Para ello es preciso conocer también el destino de la población autóctona.

En lo que se refiere al primer aspecto, se han hecho cálculos relativos al número medio de colonos por colonia, postulándose cifras que irían desde los 3000-4000 para las ciudades italianas (Keppie, 1983, 98), los 2000-3000 para cada colonia (Brunt, 1971, 238 y 259-261) hasta apenas los 1000 colonos (Mann, 1983, 59). A los colonos cabría añadir la posibilidad de participación civil, tanto de proletarii como de romanos asentados con anterioridad a la creación de la colonia. En cuanto al segundo, el establecimiento de colonos en lugares ya habitados, como en el caso de Hispalis, suponía la puesta en práctica de diversas alternativas para la población autóctona. Entre estas posibilidades se pueden mencionar su expulsión en masa, su admisión en la colonia con el derecho a un cierto grado de participación en la vida pública o su conversión en mano de obra dependiente, es decir los denominados in- colae; esta última posibilidad se ha constatado en la Colonia Romula.

Por lo tanto, la cuestión que cabe preguntarse es la de si el espacio englobado por el pomerium turdetano-republicano fue suficiente para dar cabida tanto a los colonos de César como a los de $\mathrm{Au}-$ gusto. La posibilidad de que Hispalis fuese inicialmente una colonia titular, unido a la circunstancia de que la fundación cesariana tuviese lugar como consecuencia del apoyo de la ciudad al bando pompeyano durante la guerra civil, indicio del trágico destino de parte de su población, permitiría sugerir que la concesión del estatuto colonial por César no llevó aparejada modificación alguna en su perímetro amurallado.

Por el contrario, los estudios relativos a la colonización augustea han puesto de manifiesto que la labor de Augusto se centró en obtener unas bases más estables y menos traumáticas que las de César, procediendo al asentamiento de soldados licenciados. En esta misma línea, se ha sugerido que del texto de Estrabón tradicionalmente utilizado para sostener la teoría de la doble fundación sería posible inferir ciertas deficiencias demográficas, que llevarían a Augusto a efectuar una nueva adscripción de colonos (Ordóñez, 1998, 70; 2005, 110). Por esta razón, se podría sostener también que fuera el asentamiento de veteranos por Octavio, en 1513 a.C., el responsable de la erección de un nuevo dispositivo defensivo más extenso para la Colonia Romula Hispalis. Esta circunstancia acontecía en Corduba por esas mismas fechas (Ventura et alii, 1996, 93-94; Murillo, 2004, 45; Vaquerizo et alii, 2011, 28).

Asimismo, para efectuar una aproximación a las consecuencias urbanísticas que para Hispalis tendría la concesión del estatuto colonial se puede utilizar la información procedente de asentamientos que experimentaron un proceso similar. Para ello es preciso tener en cuenta las siguientes variables: un ámbito espacial semejante, es decir en el Bajo Guadalquivir; un marco temporal parecido, esto es colonias fundadas por César y Augusto; y una misma realidad urbanística, es decir asentamientos de relativa entidad y antigua fundación elevados a la categoría de colonia civium romanorum, pues la fundación de una colonia ex novo solía ir acompañada por la erección de una cerca a lo largo de su pomerium ${ }^{2}$. Así aconteció en Emerita Augusta

2 Son abundantes los ejemplos de colonias que carecerían 
(Mateos, 2004, 28 y 30) o Caesaraugusta (Martín, 1993, 118-119; Beltrán Lloris, 1999, 412). Por el contrario, no tenemos la certeza de que en el caso de antiguos núcleos de población la fundación colonial supusiera una ampliación del perímetro amurallado.

De esta manera, y teniendo en cuenta las tres variables que acabamos de mencionar, las colonias a las que se puede recurrir para establecer un paralelismo con la Colonia Romula serían la Colonia Augusta Firma Astigi y la Colonia Genetiva Iulia Urso. Los datos disponibles en relación al impacto en el urbanismo del establecimiento de ambas colonias no son abundantes ni concluyentes. En Urso los escasos datos parecen sugerir una ampliación del espacio urbano como consecuencia de la concesión del estatuto colonial (Corzo, 1979, 121; Campos, 1989, 108-109; Pachón, 2011, 195-197). En Astigi la fundación colonial fue acompañada de un incremento de su superficie, con un urbanismo de nueva planta a base de calles que se cortan en ángulo recto (Sáez et alii, 2004, 27 ss.; 2005, 90-93; García-Dils, 2010, 87 ss.; 2011, 107 ss.; 2012: 122 ss.).

Por otra parte, el Principado de Augusto supuso una transformación del paisaje urbano como consecuencia de la intensificación de la actividad constructiva (Bendala, 1999, 131-132; Jiménez Salvador, 1999, 146; Ordóñez, 2002, 16-17; 2005, 113114). Dicha actividad se plasmó en la monumentalización de determinados ámbitos arquitectónicos, entre los que destacan los conjuntos forenses y las murallas. Ambos elementos representan el escenario privilegiado en el que se manifiestan tanto el dominio ideológico y cultural de Roma, en cuanto que cosmos nuevo y perfecto que se impone al caos representado por los bárbaros y la naturaleza, como la voluntad de representación de las nuevas élites locales; éstas van a utilizar el evergetismo o mecenazgo cívico como fórmula de promoción política (Melchor, 1994, 153). Es en este contexto donde habría que situar lo que se ha denominado "la remilitarización simbólica del paisaje" (Gros, 1996, 39).

Aunque no es posible afirmar que la citada monumentalización afectara al pomerium de Hispalis en época cesaroaugustea, las termas excavadas

de murallas (Gros, 1996, 39), a las que se ha denominado "ciudades abiertas" (Gros y Torelli, 1988, 255). Incluso se pueden mencionar casos de algunas que se negaron a erigirlas (González Acuña, 2011, 50). por Collantes en la Cuesta del Rosario sugieren que sí afectó a su conjunto forense ${ }^{3}$. Además en Abades 41-43 se documentaron los cimientos de una estancia trapezoidal de reducidas dimensiones, delimitada por cuatro muros de opus incertum dotados de zapatas de mampostería careada; su excavador le asigna una cronología que oscilaría entre mediados del siglo I a.C. y el siglo I d.C. y la relaciona con el desarrollo arquitectónico que para la ciudad debió suponer su transformación en colonia romana ( $\mathrm{Ji}-$ ménez Sancho, 2002, 142-144). Estos datos, unidos a las intervenciones augusteas en la cerca de Car$m o$, en concreto en las puertas de Córdoba (Jiménez Martín, 1977, 235; Ojeda, 2001, 183) y de Sevilla (Jiménez Martín, 1989, 196; Schattner, 2005), permiten inferir que algo se haría en las murallas de la Colonia Romula. Sin embargo, a día de hoy no es posible determinar su naturaleza y características.

De cualquier modo, fueran César (Jiménez Martín, 1981, 16) o Augusto (Corzo, 1997, 210) los impulsores de la ampliación del perímetro amurallado en la segunda mitad del siglo I a.C. esta no obedeció a una realidad urbanística. Salvo contadas excepciones, las intervenciones arqueológicas no han proporcionado estructuras de dicha cronología. Podríamos paralelizar su erección con la del siglo XII, pues en ella se incluyeron amplios espacios sin urbanizar. Si se aborda la cuestión desde esta perspectiva, se puede argumentar que las intervenciones con restos que se remontan a los siglos I-II d.C. encuentran su justificación en un emplazamiento intramuros desde la segunda mitad del siglo I a.C. Del mismo modo, en los siglos XIV y XV se urbanizaron extensas superficies intramuros desde el siglo XII.

Se puede afirmar también que en el siglo II d.C. se erigió un nuevo recinto amurallado en Hispalis. Dicha cronología encontraría un argumento a favor en el contexto histórico, puesto que es ahora cuando se erigen las murallas de la noua urbs italicense y las de Munigua (Grünhagen, 1982, 324). Sería también contemporánea de varios cambios urba-

3 Las más recientes investigaciones niegan el carácter de termas a dichos restos, vinculándolos con un amplio espacio con piletas perteneciente a una edificación de carácter diverso. Para ello se basan en la anómala disposición de las piscinas, la ausencia de muros y el carácter artesanal de los contextos precedentes (González Acuña, 2011, 483). Asimismo, estas investigaciones descartan la presencia de un espacio forense en el entorno del Salvador y la Plaza de la Alfalfa (González Acuña, 2011, 170-173). 
nísticos producidos en la Colonia Romula (González Acuña, 2011, 193).

Dichos cambios consisten en una importante transformación en la distribución de las necrópolis (González Acuña, 2011, 540), en una sustitución generalizada de los antiguos ámbitos productivos/ comerciales por una ocupación doméstica (González Acuña, 2011, 558) y en la construcción de diversas edificaciones de carácter singular. Entre éstas se incluyen varios complejos termales ${ }^{4}$, las columnas de la calle Mármoles ${ }^{5}$ y el edificio de planta rectangular documentado en la Plaza de la Pescadería e identificado con el castellum aquae ${ }^{6}$ (García García, 2007a, 11 y 19; 2007b, 137). En esta misma línea, se pueden añadir las estructuras documentadas en Alemanes 25 y parcelas aledañas, donde en época antonina se erigió una edificación de grandes piedras calizas sobre una superficie aterrazada (Vázquez, 2010, 3170), Placentines 7, con una estructura de hormigón sobre el que se dispuso como cimentación un encofrado de la misma naturaleza, mientras que el alzado consistiría en una fábrica de ladrillo, fechada en torno al siglo II d.C. (Fernández Flores y Rodríguez Azogue, 2003, 962 ss.), la reforma adrianea de la edificación documentada en Francos 41 (Rodríguez Hidalgo, 1998) y tal vez la reorganización urbanística que se ha sugerido en la Plaza de la Virgen de los Reyes entre Tiberio y los Severos (Romo, 1999, 432).

Por lo tanto, la erección de la muralla en este momento sí que obedecería a una realidad urbanística. Son muy numerosas las intervenciones arqueológicas, llevadas a cabo al interior del hipotético pomerium imperial, que han revelado una estructura urbana plenamente consolidada a mediados del siglo II d.C.

4 Las termas documentadas en la Colonia Romula se localizan en la Cuesta del Rosario (Collantes de Terán, 1977, 63 y 70-72; Vera Reina, 1987, 55; González Acuña, 2011, 487), la calle Abades (Jiménez Martín, 1985, 8-9; Corzo, 1991, 74 ss.; González Acuña, 2011, 491) y el Palacio Arzobispal (Larrey y Verdugo, 1995, 566 ss.).

5 La historiografía sevillana atribuye a las columnas de la calle Mármoles una cronología del siglo II d.C. (Blanco, 1972, 20; 1979, 135; Blanco y Corzo, 1976, 143; Jiménez Martín, 1985, 8; Campos y González, 1987, 129; Márquez, 2003). No obstante, las últimas investigaciones al respecto vinculan su erección con un gran complejo eclesiástico, identificado con la sede episcopal y fechado hacia el siglo VI d.C. (González Acuña, 2011, 181-192 y 196).

6 Hay quienes han sugerido que se trate de una cisterna de almacenamiento y depósito de agua que formara parte de la red de distribución (Ordóñez y González Acuña, 2009, 70).

\subsection{LAS CARACTERÍSTICAS ARQUITECTÓNICAS DE} LAS MURALLAS DE HISPALIS.

Si centramos nuestra atención en las características arquitectónicas de los restos que se han vinculado con las murallas de Hispalis, de su análisis resulta evidente que no todos se erigieron con la misma técnica (Valor, 1991, 60). A pesar de que la historiografía sevillana haya considerado que todos los restos identificados con la muralla de la Colonia Romula pertenecen a la cerca imperial de Hispalis (Campos, 1993, 194), no es posible sostener la hipótesis de que pertenecieron a un mismo recinto defensivo. Por el contrario, lo que aquí sostenemos como más plausible es que dichos restos no formaron parte al mismo tiempo de la cerca de la Colonia Romula, puesto que Hispalis habría dispuesto de al menos dos recintos amurallados. El principal argumento para sostener la existencia de sendos recintos romanos, aparte de ciertas consideraciones de carácter arqueológico que hemos expuesto en otro lugar, lo constituye las descripciones de los restos vinculados con las defensas de la Sevilla romana. Es posible detectar en ellos distintas técnicas constructivas que podrían representar diferentes cronologías.

- Lienzos erigidos con lo que parecía ser opus caementicium. Al respecto Collantes aludió a derretido de $2 \mathrm{~m}$ de grosor en la calle Orfila, aunque ahora sabemos que se trata de tapial (Oliva, 2008). Asimismo, los restos de la Avenida de la Constitución podrían pertenecer a estructuras de carácter portuario (Ordóñez, 1998, 157-159).

- Lienzos erigidos con dos paramentos de piedra con un relleno de argamasa y piedra de no muy buena calidad, como en la calle Martín Villa. Para este lienzo Collantes ya apuntó la posibilidad de que constituyese la evidencia de una ampliación del perímetro amurallado en este punto (Collantes de Terán, 1977, 75). Por su parte, Carriazo hace mención a fortísimo mortero que estuvo paramentado de sillería al final de la Avenida de la Constitución.

- Lienzos erigidos con sillares y una anchura similar, como el lienzo de piedra labrada de más de $2,50 \mathrm{~m}$ de anchura de Santa Catalina, el de la Plaza de Villasís, cuyo espesor alcanzaba los $3 \mathrm{~m}$, y el de la Encarnación, con sillares de piedra alcoriza dispuestos en opus quadratum y $4 \mathrm{~m}$ de anchura.

Una vez que hemos evidenciado las diferencias existentes en las técnicas empleadas en los lienzos vinculados a las defensas hispalenses, el siguiente paso consiste en determinar la cronología de cada 


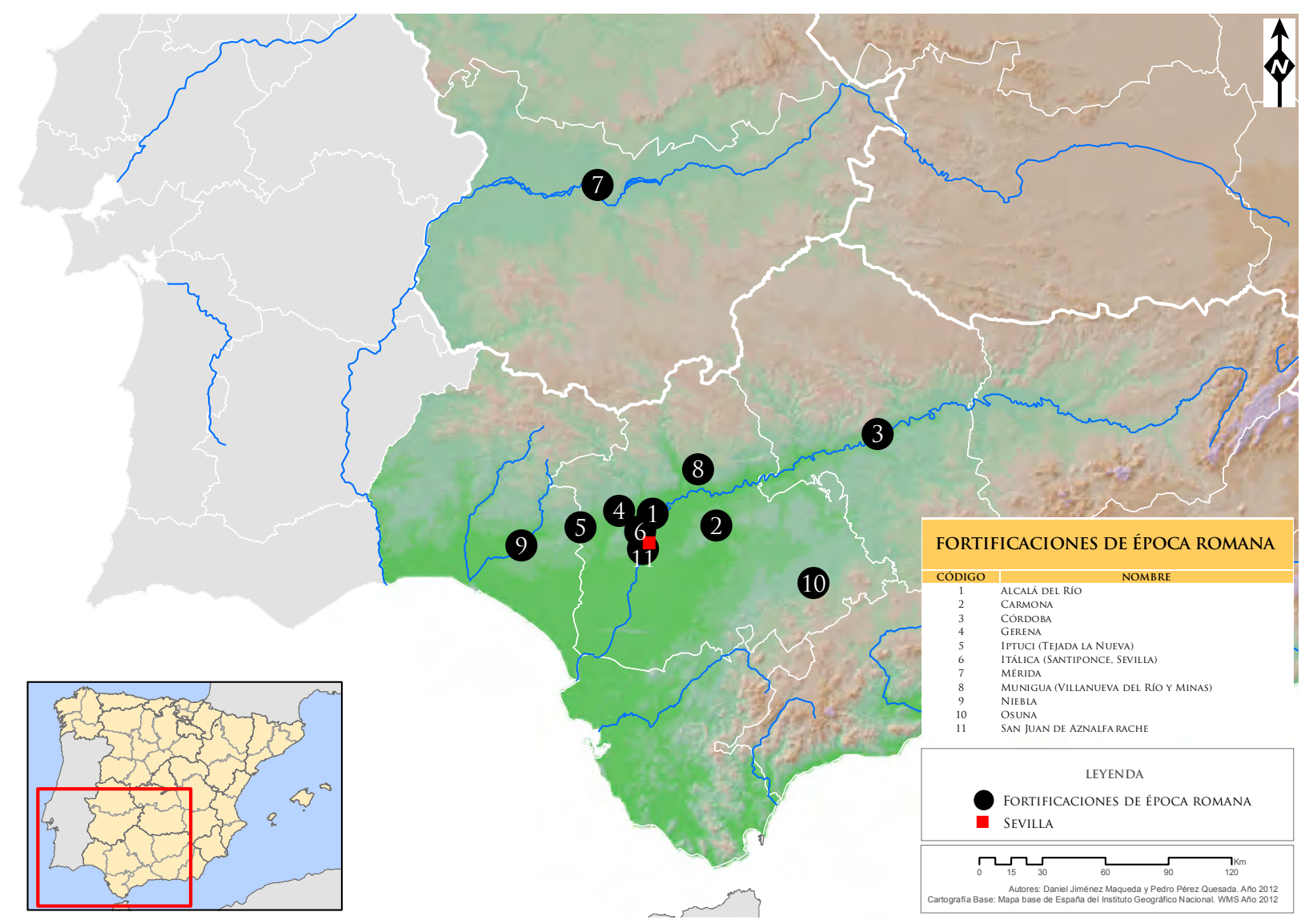

Figura 9. Localización de las fortificaciones romanas.

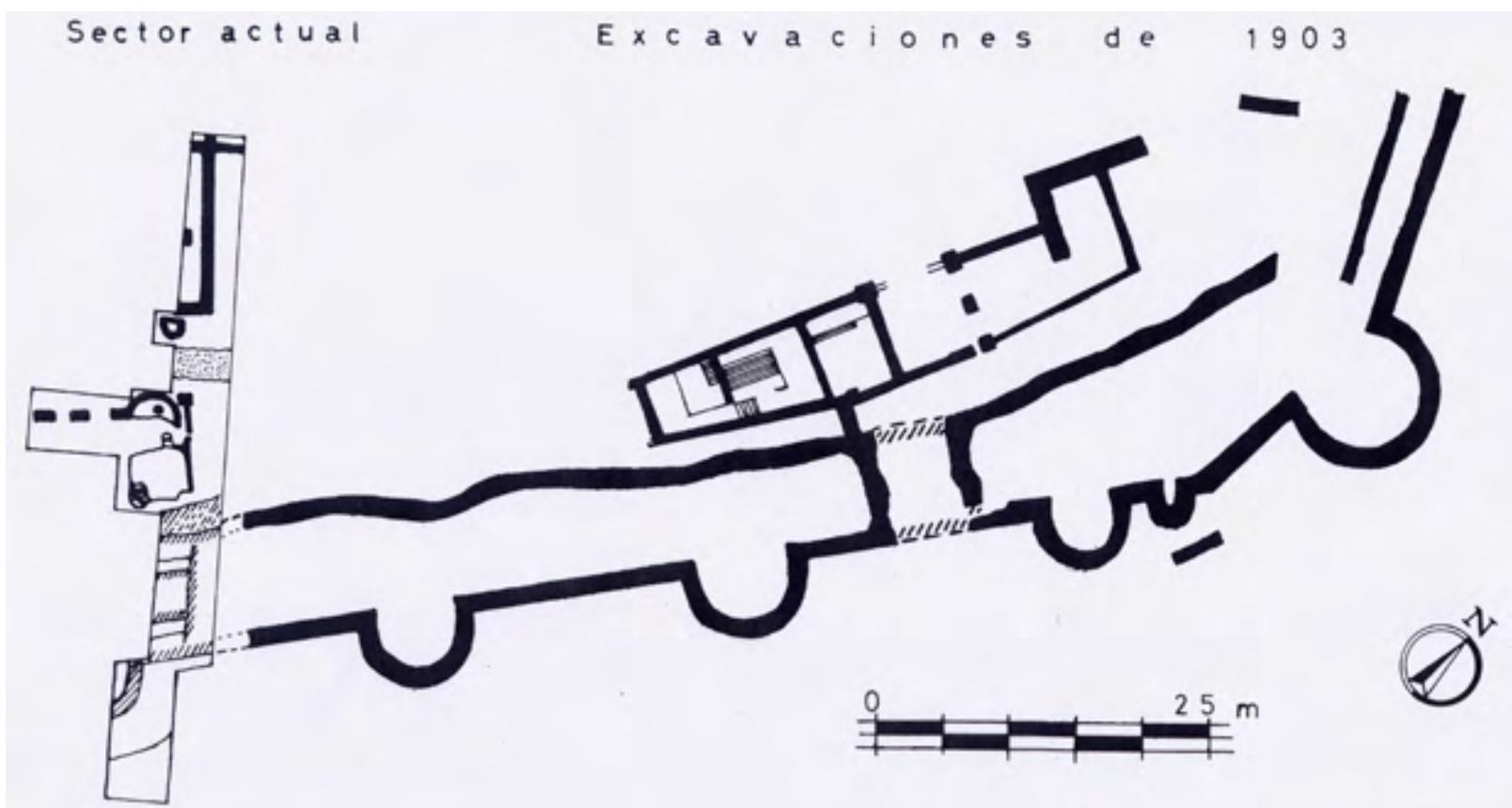

Figura 10. Hipótesis de reconstrucción de las murallas de Urso, Osuna, Sevilla, según Corzo (1977a). 
uno de ellos. Para esta tarea utilizaremos las murallas del entorno más inmediato de Hispalis, comparando las técnicas constructivas documentadas en ellas con las sevillanas (figura 9). Ahora bien, la mayor dificultad al respecto estriba en que la datación tipológica requiere analogías datables (Lander, 1984, 151) y estas no son especialmente abundantes en Andalucía Occidental ${ }^{7}$. Además, en lo que se refiere a las fortificaciones romanas no es muy conveniente trasladar la casuística de una zona a otra, ni siquiera de un recinto a otro. Al respecto, parece muy probable que en la erección de cada recinto desempeñaran un papel determinante las circunstancias peculiares de cada ciudad. Entre dichas circunstancias se pueden mencionar su actividad económica, su vitalidad, supuestas amenazas exteriores e incluso razones de prestigio (Rebuffat, 1986).

En primer lugar, el posible empleo del opus caementicium en el recinto más antiguo permitiría sugerir una cronología augustea para el mismo, basándonos para ello en dos argumentos. No es posible relacionar con ningún resto sevillano las murallas republicanas de Urso, erigidas durante las Guerras Civiles entre el 50 y el 45 a.C., si bien hay investigadores que sostienen una cronología más antigua (Escacena, 2002, 85, 88 y 89; Salas, 2002, 99; Hourcade, 2003; Pachón y Ruiz Cecilia, 2005). Estas murallas se caracterizan por un núcleo a base de varios muros de piedra, que conforman espacios rellenos de tierra, arena y piedras, paramento exterior en talud, un terraplén en su cara interior y torres semicirculares (figura 10) (Engel y Paris, 1906, 380 ss.; Corzo, 1977a, 13 ss.; 1977b, 137). Por su parte, hay cierta similitud entre alguno de los restos atribuidos al pomerium de Hispalis y la muralla más antigua de Italica y la de Ilipa Mag-

7 Las intervenciones de Engel y Paris y Corzo en Osuna (Engel y Paris, 1906; Corzo, 1977a; 1977b); las del Instituto Arqueológico Alemán en Munigua (Grünhagen, 1982; Schattner, 2003, 52 ss.); la del Instituto Andaluz del Patrimonio Histórico en la Puerta de Córdoba en Carmona (Ojeda y Tabales, 1996; Ojeda, 2001); las de la Puerta de Sevilla (Gómez et alii, 2001, 115, 117 y 119; Campos et alii, 2006, 219) y sus lienzos inmediatos en Niebla (Gómez y Beltrán Pinzón, 2006, 647-648; Campos et alii, 2006, 273-274); las llevadas a cabo en diversos puntos de Alcalá del Río (Izquierdo, 2007; 2009; Prados, 2007; Taylor, 2010; Villa, 2010); la de San Juan de Aznalfarache en el transcurso de las obras de la línea 1 del metro de Sevilla (Pozo et alii 2006, 208); y las efectuadas en el casco histórico de Córdoba (Ibáñez, 1990; Botella, 1995; Aparicio, 2001; Ruiz Nieto, 2002; 2003; López, 2002; Rodero et alii, 2003; Carrasco et alii, 2003; Molina, 2005; 2009; Valdivieso, 2010).

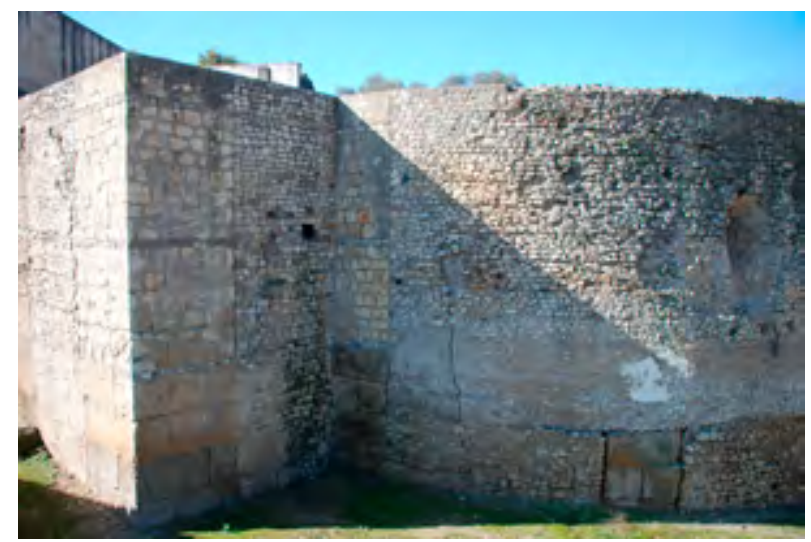

Figura 11. Muralla de la uetus urbs de Italica, Santiponce, Sevilla (fotografía cortesía de José Manuel Rodríguez Hidalgo).

na. Así tradicionalmente se ha sostenido que la de Itálica se habría erigido en opus caementicium con paramento de opus incertum, dotada de torres circulares (figura 11) y se habría fechado tanto a finales de época republicana (Corzo, 1982, 310; Jiménez Martín, 1977, 230) como en época de Augusto (Roldán, 1993, 42; Caballos et alii, 1999, 58 y 63). No obstante, recientemente se ha interpretado la torre circular junto al teatro como una exedra exterior perteneciente a una plaza pública (Jiménez, 2009: tomo 1, 32). En cuanto a la de Ilipa Magna, con una cronología de principios del siglo I d.C., consiste en una obra de opus caementicium, a base de piedras de mediano tamaño unidas con mortero que contiene una alta proporción de cal, y torres cuadrangulares que se proyectan a ambos lados de la cerca (figura 12) (Izquierdo, 2007; 2009; Prados, 2007; Romo et alii, 2002; Villa, 2010, 4139). Recientemente se ha documentado una torre circular (Taylor, 2010).

Por otra parte, la presencia entre los lienzos sevillanos de restos erigidos con dos paramentos de sillares e interior de argamasa y piedra permite plantear tres hipótesis relativas a su cronología. La primera consiste en que su erección fuese contemporánea de las fortificaciones romanas de Niebla y Tejada la Nueva en Huelva y Alcalá del Río, Gerena (figura 13) y Carmona en Sevilla ${ }^{8}$. Para todas ellas se ha sostenido como cronología el siglo II d.C. (Blanco y Corzo, 1976, 159-160; Corzo, 1977a,

8 Niebla (Jiménez Martín, 1977, 224-226), Tejada la Nueva (Jiménez Martín, 1977, 226-227), Alcalá del Río (Hernández et alii, 1939, 92, Thouvenot, 1940, 390; Jiménez Martín, 1977, 231-233), Gerena (Hernández et alii, 1955, 170, 178 y 179; Jiménez Martín, 1977, 227-229) y Carmona (Thouvenot, 1940, 392 ss.; Jiménez Martín, 1977, 233-226; 1989, 187 ss.). 


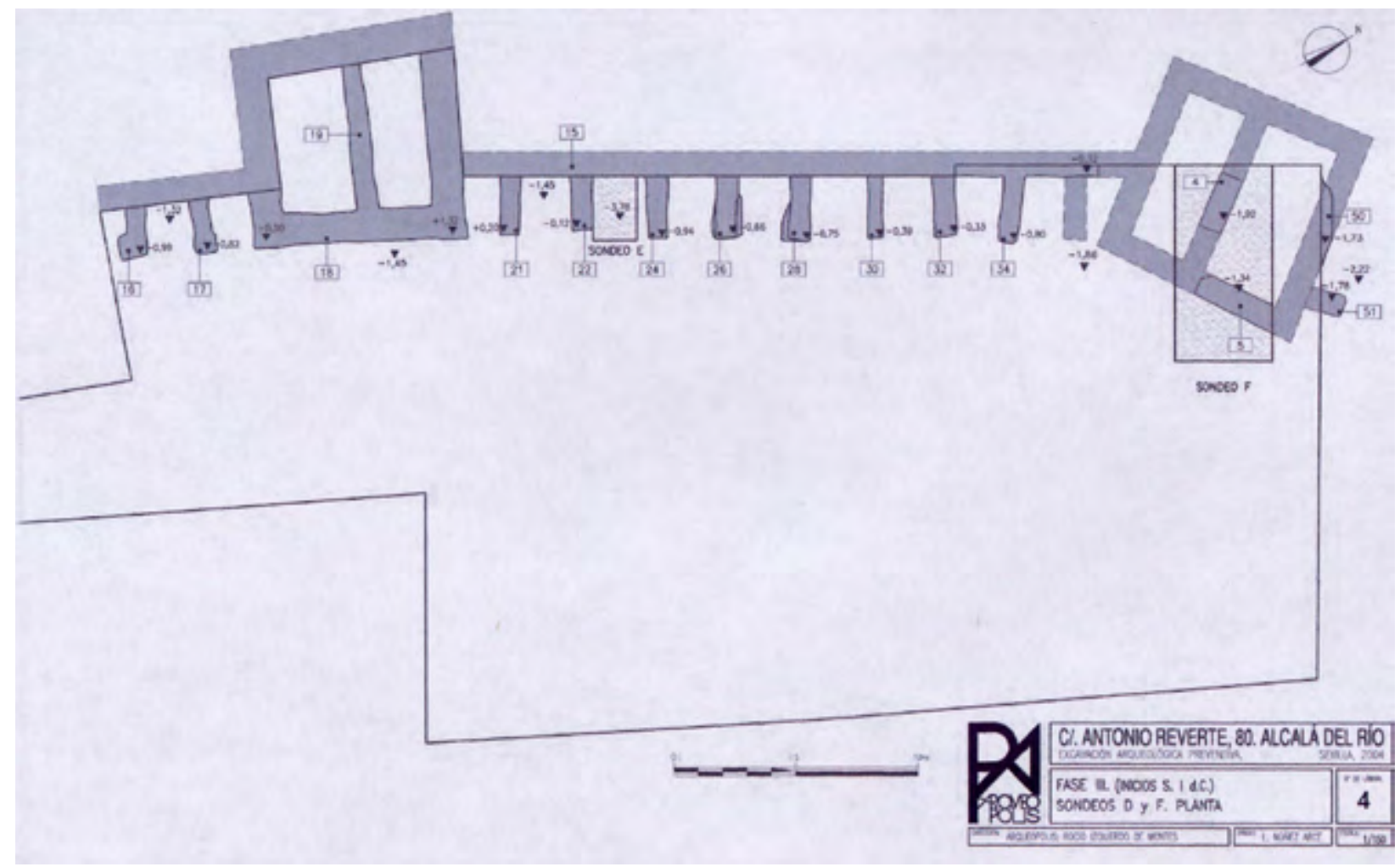

Figura 12. Planta de la muralla romana documentada Antonio Reverte 80 de Alcalá del Río, Sevilla, según Izquierdo (2009).

17-18) y las guerras sertorianas (Jiménez Martín, 1977, 237). Esta última datación parece demasiado precoz para el caso hispalense, aunque hace años Blanco sostuvo incluso que las sevillanas se erigieron como consecuencia de las incursiones lusitanas en la Ulterior en el siglo II a.C. (Blanco, 1972, 14$15 ; 1979,116)$. En relación a este punto, las intervenciones arqueológicas efectuadas en Córdoba han documentado diversos tramos de la muralla erigida a lo largo del segundo cuarto del siglo II a.C. Todos ellos se caracterizan por sendos lienzos paralelos, el exterior muestra una anchura entre los 2 y $3 \mathrm{~m}$ y está configurado por grandes sillares dispuestos en hiladas alternas de soga y tizón. El interior es más bajo y estrecho, separado del primero por un terraplén de $6 \mathrm{~m}$ de anchura y cantos rodados, mampostería y arcilla (Escudero et alii, 1999, 202203; Murillo y Jiménez Salvador, 2002, 187; Muri1lo, 2004, 43; 2006, 349-350; Molina y Valdivieso, 2007; Vaquerizo et alii, 2011, 12-13).

La segunda hipótesis consiste en defender una cronología similar a la de la muralla de la noua urbs italicense, erigida en la primera mitad del siglo II d.C. (figura 14) (Jiménez Martín, 1977, 230;
Roldán, 1993, 47; Caballos et alii, 1999, 32 y 62). Todos los investigadores coinciden en señalar que no tendría carácter defensivo, sino tan sólo simbólico y administrativo (Jiménez Martín, 1977, 231; Corzo, 1982, 315; Pellicer, 1982, 233; Roldán, 1993, 42 y 47; Caballos et alii, 1999, 63). Con ella parece compartir varias características el lienzo registrado por Collantes en el transcurso de las obras de

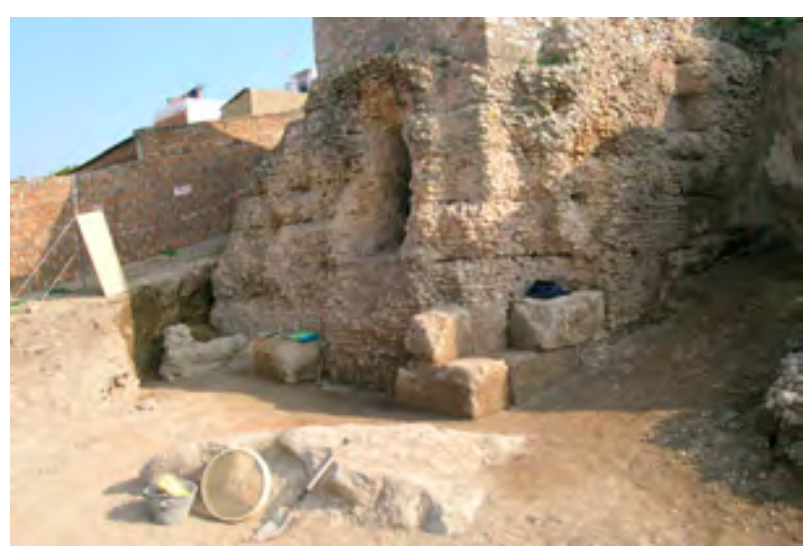

Figura 13. Torre del recinto romano de Gerena, Sevilla (fotografía cortesía de José Manuel Rodríguez Hidalgo). 
alcantarillado de la calle Martín Villa. En Italica la anchura oscila en torno al 1'50 m (Roldán, 1993, 46), mientras que en Sevilla no supera los $2 \mathrm{~m}$; estas diferencias las hay que atribuir a la desaparición de los sillares en Italica. En lo que al relleno se refiere, en ambos casos la obra no es de gran calidad constructiva, pues en Italica la argamasa es poco consistente (Roldán, 1993, 45), mientras que Collantes alude a un relleno de no muy buena calidad en Martín Villa.

La tercera hipótesis supone la posibilidad de que la nueva cerca hispalense fuera contemporánea de la de Munigua, erigida de manera apresurada para hacer frente a las incursiones de los mauri en la Bética, a comienzos de la década de los años setenta del siglo II d.C. (figura 15) (Grünhagen, 1982; Schattner, 2003, 52 ss.). Dicha cronología se defendió hace años para las murallas andaluzas erigidas a base de dos paramentos de sillares y relleno de opus caementicium (Corzo, 1977a, 17-18).

Finalmente, la presencia de restos en los que tan sólo se alude a la piedra como material de construcción se puede interpretar de tres maneras. La concesión del estatuto colonial a Hispalis fue acompañado de la erección de un nuevo recinto amurallado en el que se emplearon sillares. Con dicho recinto se podrían relacionar los hallazgos de la Parroquia de Santa Catalina y la Plaza de Villasís y los restos excavados en la Encarnación y en el Patio de Banderas del Alcázar. Como quiera que para ambas estructuras se ofrece una datación diferente, aquéllas de mediados del siglo I d.C. mientras que éstas entre los años 60-30 a.C., se puede sostener que la cerca de la Colonia Romula no se levantara en un

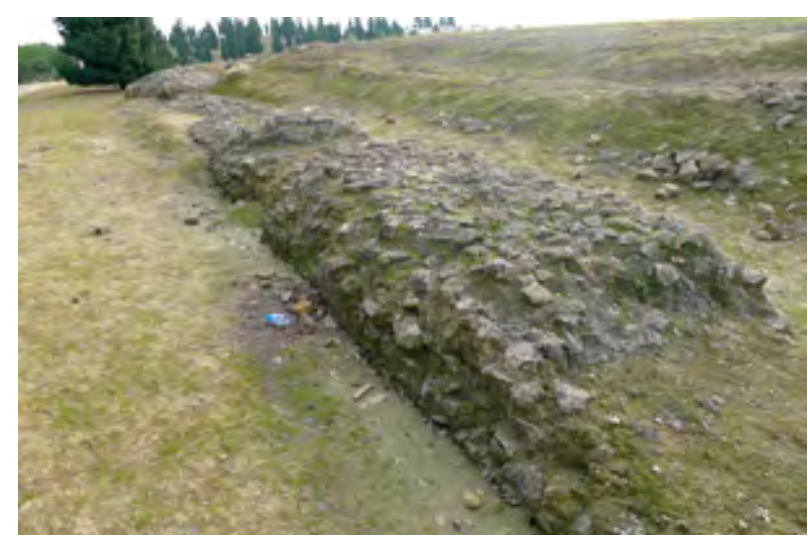

Figura 14. Muralla de la noua urbs de Italica, Santiponce, Sevilla (fotografía cortesía de José Manuel Rodríguez Hidalgo).

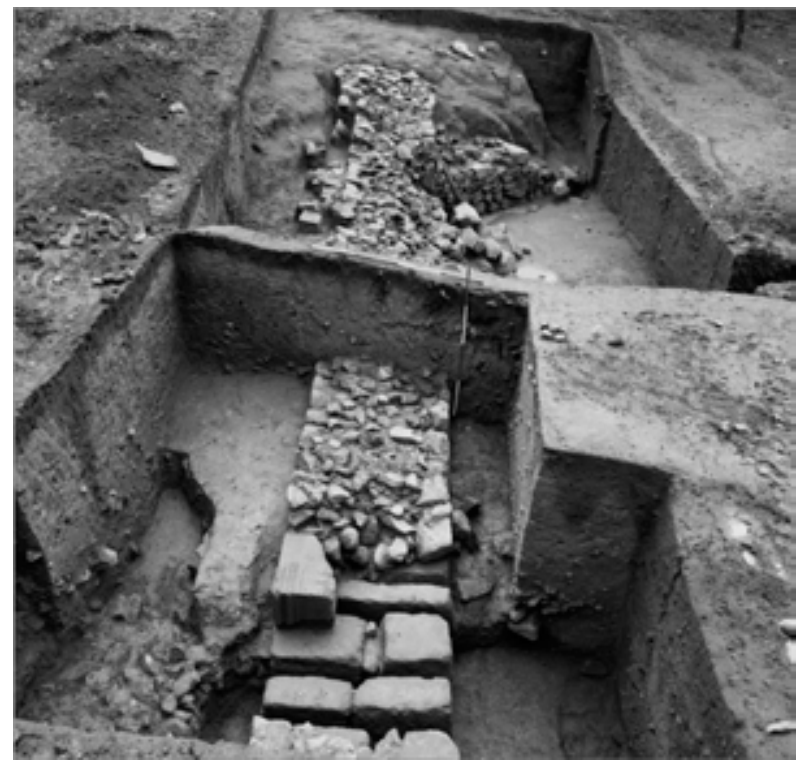

Figura 15. Lienzo septentrional del recinto amurallado de Munigua, Villanueva del Río y Minas, Sevilla (fotografía cortesía del Instituto Arqueológico Alemán).

único impulso constructivo. Sabemos que así aconteció en la ampliación del recinto amurallado de Corduba hacia el río, pues sería proyectada y quizás comenzada en época de Augusto, pero concluida bajo sus sucesores ${ }^{9}$ (Murillo, 2004, 45 ss.; León Muñoz et alii, 2008, 266 y 268). En virtud del emplazamiento de alguno de ellos en puntos donde la historiografía sevillana se muestra unánime en localizar sendos accesos de la cerca imperial romana, en segundo lugar se puede plantear la hipótesis de que los restos de la Parroquia de Santa Catalina y la Plaza de Villasís formaran parte del dispositivo defensivo de alguno de los accesos de Hispalis. En relación a este punto, cabe recordar cómo en la Puerta de Córdoba de Carmona, erigida según sus excavadores a fines del siglo I a.C. o comienzos del I d.C., se utilizó el opus quadratum (Ojeda, 2001, 166). La última posibilidad supone que los lienzos de Santa Catalina y la calle Villasís pertenecieran a la cerca erigida por 'Abd al-Rahmān II en el 844, tras el saqueo de Išbīlia por los normandos.

9 Las excavaciones efectuadas en el lienzo meridional de la ampliación augustea han documentado, en el Paseo de la Ribera, muros erigidos con sillares de calcarenita, dispuestos a soga y tizón, tomados con mortero de cal y arena y calzados con ripios y cantos, a los que se atribuye una cronología julio-claudia (Rodero et alii, 2003). 


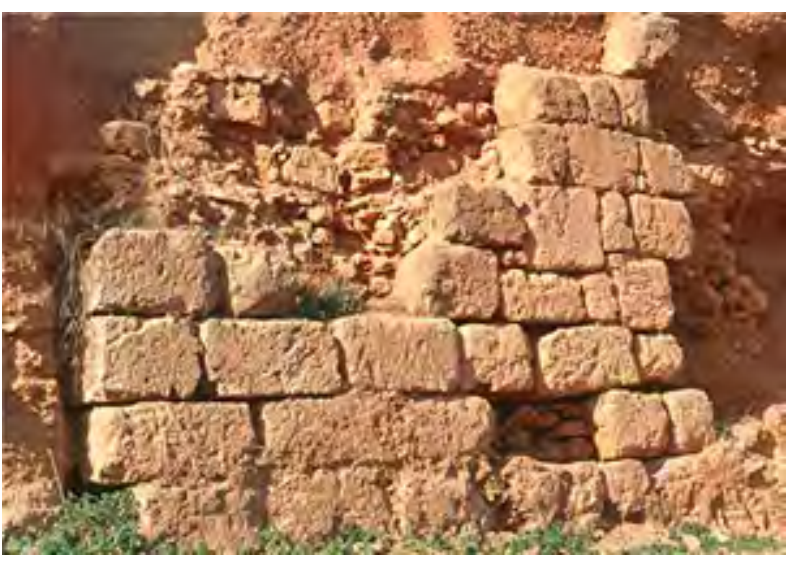

Figura 16. Restos de la muralla romana de Niebla, Huelva (fotografía cortesía de Juan Manuel Campos).

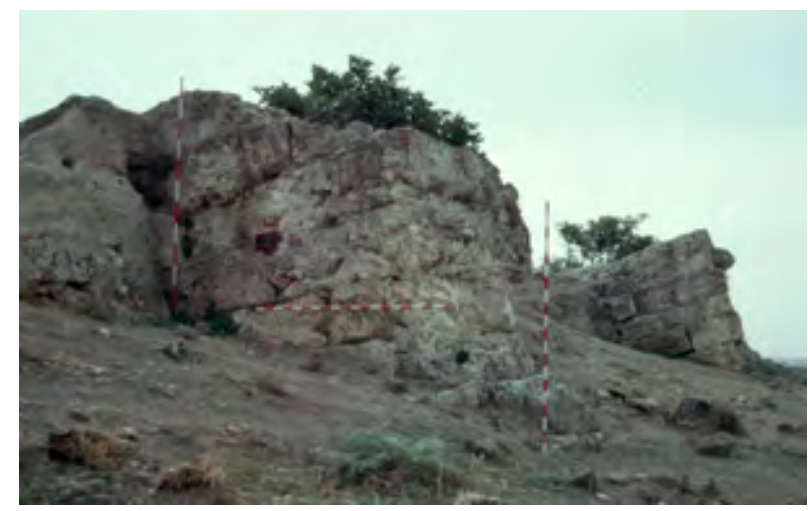

Figura 17. Torres 5 y 6 del recinto romano de Tejada la Nueva, Escacena del Campo, Huelva (fotografía cortesía de Juan Manuel Campos).

\section{A MODO DE SÍNTESIS.}

En relación al pomerium de la Colonia Romula sugerimos la existencia de al menos dos expedientes constructivos. A este respecto resultan muy sugerentes las ideas de Vioque, Vera y López, quienes ya en los años 80 dibujaron sendos recintos diferentes para el 50 a.C. y para el siglo II d.C. (Vioque et alii, 1987, 210-213). Igualmente resultan de sumo interés las afirmaciones de Amores relativas a que Hispalis habría dispuesto de varias cercas entre la República y la conquista musulmana, calificando de entelequia la existencia de una sola muralla romana (Amores, 2005, 157).

En este sentido, a lo largo de la segunda mitad del siglo I a.C. se debió intervenir en el recinto amurallado de Hispalis. Esta intervención sería contemporánea de la concesión del estatuto colonial por César, en el 45 a.C., o de la segunda deducción de colonos por parte de Augusto, hacia el 15-13 a.C.

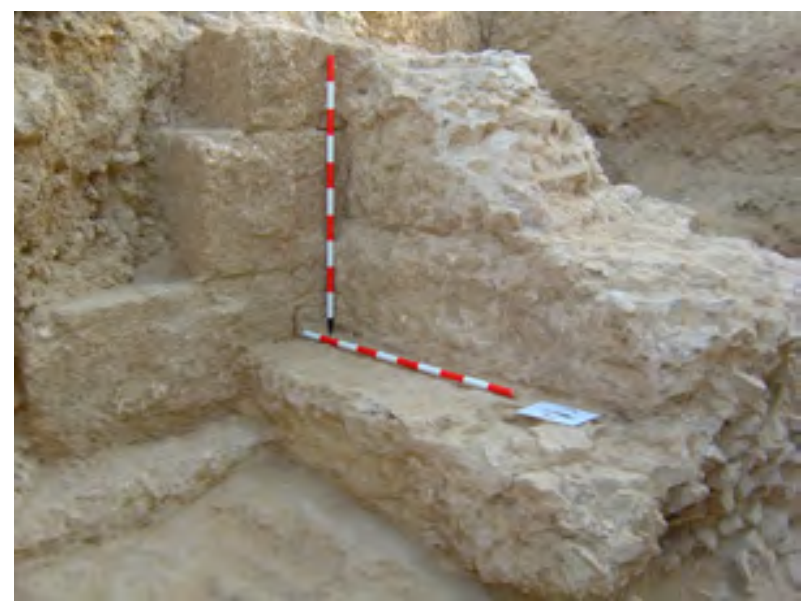

Figura 18. Muralla romana documentada, en el transcurso de las obras de la línea 1 del metro de Sevilla, en San Juan de Aznalfarache, Sevilla (fotografía cortesía de Laura Mercado).

En el estado actual de nuestros conocimientos no es posible determinar en qué medida se ampliaron las dimensiones de la cerca turdetano-republicana. En cuanto a su aspecto, la primera muralla de la Colonia Romula se erigiría en opus caementicium con paramentos de opus incertum. En esta afirmación nos basamos en las características arquitectónicas de las estructuras tradicionalmente identificadas con la muralla de la uetus urbs de Itali$c a$, para la que se ha sostenido una cronología tanto de finales de época republicana como augustea, y en las de Ilipa, fechada a comienzos del siglo I d.C. Sin embargo, los restos que más recientemente se han identificado con el pomerium de Hispalis en la Encarnación y tal vez en el Patio de Banderas se erigieron con sillares, como aconteció en la ampliación del recinto amurallado de Corduba hacia el río. Por otra parte, los datos proporcionados por las intervenciones arqueológicas ponen de manifiesto la ausencia de niveles de la segunda mitad del siglo I a.C. Si se hubiese producido entonces una ampliación del perímetro amurallado se trataría de una decisión fundamentalmente política.

Asimismo, durante el siglo II d.C. se procedería a erigir una nueva cerca que abarcase una superficie más amplia que el recinto cesaraugusteo. Al respecto es posible plantear dos posibilidades. En primer lugar, que dicha cerca fuese contemporánea de la erigida alrededor de noua urbs italicense por el emperador Adriano. De esta manera su función sería administrativa y simbólica más que propiamente defensiva. En segundo, que se cons- 
truyese con una funcionalidad defensiva para hacer frente a las incursiones de los mauri del otro lado del Estrecho. Si se toman en consideración las características arquitectónicas de la muralla de la noua urbs italicense, la de Hispalis constaría de un núcleo de opus caementicium y paramento de sillares. A dicha tipología parece responder algún lienzo vinculado por la historiografía con la muralla imperial romana, como el de la calle Martín Villa. Por lo tanto, el recinto amurallado de Hispalis sería similar al de varios recintos de la Baetica, para los que se ha sostenido una cronología tanto del primer cuarto del siglo I a.C. (Jiménez Martín, 1977, 237) como del siglo II d.C. (Blanco y Corzo, 1976, 159-160; Corzo, 1977a, 17-18). En esta línea, algunos se han excavado en los últimos años con dataciones diversas ${ }^{10}$. Además, y al contrario de lo que acontecía para la segunda mitad del siglo I a.C., la arqueología revela la presencia habitual en el registro sevillano de niveles del siglo II d.C. A este extremo, habría que añadir la remodelación urbanística a gran escala que experimentó la Colonia Romula entre finales del siglo I y mediados del II d.C. (González Acuña, 2011, 193).

En fin, en vista de los datos de los que se dispone hoy en día es posible sostener la existencia de al menos tres recintos amurallados durante la dominación romana de Hispalis ${ }^{11}$.

10 El de Niebla, que consta de paramentos de sillares de disposición irregular y núcleo de mampostería trabada con barro y dispuesta en tongadas horizontales de 0'50 metros de altura media, se fecha a fines del siglo I o principios del II d.C. (figura 16) (Gómez y Beltrán Pinzón, 2006, 647-648; Campos et alii, 2006, 273-274 y 351); el de Tejada la Nueva, con un podium realizado a base de sillares sobre el que se superpone un cuerpo de opus caementicium forrado de sillares, se fecha en el cambio de Era (figura 17) (Campos y Vidal, 1999, 231-232; 2003, 55-56; Vidal, 2007, 209); el de San Juan de Aznalfarache es de carácter monumental, con forro de sillares y al que se asigna una cronología julio-claudia (figura 18) (Pozo et alii, 2006, 208); y en Alcalá del Río se ha sugerido una reforma de la cerca de principios del siglo I d.C. en virtud de las diferencias documentadas en los materiales y técnicas constructivas de los lienzos de la calle Pasaje Real 2-4 en relación a los restantes (Izquierdo, 2007, 204), mientras que en la cara norte de una de las torres excavadas en Antonio Reverte 80 se documentó un sillar de piedra alcoriza, adosado a una de sus caras y dispuesto a soga, y el negativo de otro no conservado dispuesto a tizón (Izquierdo, 2009, 3053).

11 No se pueden descartar modificaciones en época tardorromana y/o visigoda, si bien en este último caso excedería de los límites temporales de nuestro trabajo. Sabemos que así aconteció en Italica, en Córdoba o en Mérida, por citar sólo los ejemplos más cercanos. En este orden de cosas, algún autor ha relacionado la estructura documentada en el número 16 del
El más antiguo lo constituye el que se menciona en sendos pasajes relativos al enfrentamiento entre César y los partidarios de Pompeyo (Bell. Hisp. 35-36). Su trazado sería muy similar al prerromano, por lo que lo denominamos turdetano-republicano, extremo en el que coincidimos con González Acuña (González Acuña, 2011, 65).

El segundo sería contemporáneo de la concesión por César del estatuto colonial a Hispalis, en el 45 a.C., o de la segunda deducción de colonos por parte de Augusto, hacia el 15-13 a.C. La formalización de este recinto pudo comprender un amplio lapso temporal, como sucedió en la ampliación del recinto amurallado de Corduba hacia el río, proyectada y quizás comenzada en época de César o Augusto, pero concluida bajo sus sucesores. De este modo si la estructura documentada en la Encarnación fuese un lienzo de la cerca se podría vincular con este proceso ${ }^{12}$. Por último, en el estado actual de nuestros conocimientos, no es posible determinar en qué medida se aumentaron las dimensiones del pomerium del recinto turdetano-republicano. Con todo

Patio de Banderas del Alcázar con dichas modificaciones (González Acuña, 2011, 63).

En Italica las prospecciones de los años 90 del pasado siglo detectaron una potente muralla, a la que se asignó una cronología de fines del siglo III o principios del IV d.C. y que reduce su superficie a menos de 27 hectáreas (Rodríguez Hidalgo, 1997, 108; Rodríguez Hidalgo et alii, 1999, 79, 81 y 94; Caballos et alii, 1999, 62). En el siglo VI d.C. las fuentes históricas informan de una restauración de las murallas efectuadas por el soberano visigodo Leovigildo.

En Córdoba en los siglos VI-VII d.C. se procedió al cerramiento de uno de los vanos laterales de la puerta del puente, erigida en época julio-claudia, que comunicaba el pórtico con la escalinata de acceso a la ribera del Guadalquivir (Carrasco et alii, 2003, 290). En el siglo VI d.C. se erigió una fortificación en la esquina sudoccidental del recinto amurallado de la Colonia Patricia, realizado con sillares e identificado con un castellum (León Muñoz et alii, 2008, 269-270).

En Mérida la muralla augustea experimentó una reforma hacia el siglo V d.C. Consistió en tapiar las puertas o disminuir la amplitud de sus vanos y en forrar aquella con un muro de material reutilizado a base de sillares de granito, con abundante material funerario (Mateos, 2004, 31-32; Álvarez, 2007, 655).

Por otra parte, son diversas las localidades de Hispania que se dotaron de recintos amurallados en época bajoimperial (Fernández Ochoa y Morillo, 1991; 1992; 2002).

12 La lectura de la tesis doctoral de uno de sus excavadores sugiere la posibilidad de que se vinculase a la tercera asignación de colonos promovida por el emperador Otón, en el año 69 d.C. (González Acuña, 2011, 403, 555 y 556). Como se ha señalado que la misma no la pudo llevar a cabo de modo efectivo el propio Otón (Ordóñez, 1998, 167 ss.; 2002, 20; 2005, 115-116) habría que atribuir la erección del supuesto lienzo de la Encarnación a la labor de la dinastía flavia. 


\begin{tabular}{|c|c|c|c|}
\hline CÓDIGO & LOCALIZACIÓN & BIBLIOGRAFÍA & CARACTERÍSTICAS \\
\hline 1 & Avenida de la Constitución & $\begin{array}{l}\text { Carriazo }(1974- \\
1975)\end{array}$ & $\begin{array}{l}\text { Mortero con paramentos de } \\
\text { sillería }\end{array}$ \\
\hline 2 & Calle Gallegos & Campos (1991) & $\begin{array}{l}\text { Muros de sillares de gran espesor } \\
\text { con el dado del espigón de una } \\
\text { puerta }\end{array}$ \\
\hline 3 & $\begin{array}{l}\text { Calle Martín Villa (frente a los } \\
\text { números } 7 \text { y } 8 \text { ) }\end{array}$ & $\begin{array}{l}\text { Collantes de Terán } \\
\text { (1977) }\end{array}$ & $\begin{array}{l}\text { Paramentos de piedra con un } \\
\text { relleno de piedra y argamasa de } \\
\text { 1'95 m de espesor }\end{array}$ \\
\hline 4 & Calle Orfila & $\begin{array}{l}\text { Collantes de Terán } \\
\text { (1977) }\end{array}$ & $\begin{array}{l}\text { Muro de derretido de } 2 \mathrm{~m} \text { de } \\
\text { espesor }\end{array}$ \\
\hline 5 & $\begin{array}{l}\text { Capilla del Rosario y del Sagrario } \\
\text { de la Parroquia de Santa Catalina }\end{array}$ & $\begin{array}{l}\text { Collantes de } \\
\text { Terán (1977) }\end{array}$ & $\begin{array}{l}\text { Piedra labrada de más de } 3 \text { varas } \\
\text { de grueso }\end{array}$ \\
\hline 6 & Casa de Miguel de Mañara & $\begin{array}{l}\text { Ojeda (1993 y 1991) } \\
\text { y Ojeda y Tabales } \\
\text { (1994) }\end{array}$ & Muro de sillares ciclópeos \\
\hline 7 & $\begin{array}{l}\text { Mercado de la Encarnación (V } \\
\text { fase de intervención) }\end{array}$ & $\begin{array}{l}\text { Amores y González } \\
\text { Acuña (2004, 2006a } \\
\text { y 2006b ) y González } \\
\text { Acuña }(2011)\end{array}$ & $\begin{array}{l}\text { Sillares de piedra alcoriza } \\
\text { dispuestos en opus quadratum }\end{array}$ \\
\hline 8 & $\begin{array}{l}\text { Número } 16 \text { del Patio de Banderas } \\
\text { del Alcázar }\end{array}$ & $\begin{array}{l}\text { Tabales }(2002 \mathrm{a}, \\
2002 \mathrm{~b}, 2002 \mathrm{c} \text { y } \\
2010 \mathrm{~b})\end{array}$ & $\begin{array}{l}\text { Alineación de sillares de piedra } \\
\text { alcoriza y módulo romano con } \\
\text { llagas irregulares y cuñas de grava }\end{array}$ \\
\hline 9 & $\begin{array}{l}\text { Parroquia de San Martín (torre del } \\
\text { campanario) }\end{array}$ & $\begin{array}{l}\text { Campos }(1991 y \\
1993)\end{array}$ & Muros de 2’70 m de espesor \\
\hline 10 & Patio de Banderas del Alcázar & $\begin{array}{l}\text { Tabales }(2010 \mathrm{c}) \text { y } \\
\text { Vargas Lorenzo }(2010)\end{array}$ & $\begin{array}{l}\text { Alineación de sillares } \\
\text { almohadillados, aparejo de opus } \\
\text { quadratum en hiladas alternas } \\
\text { a soga y tizón, cuñas de piedra y } \\
\text { emplecton interior }\end{array}$ \\
\hline 11 & Plaza de Villasís & $\begin{array}{l}\text { Collantes de Terán } \\
\text { (1977) }\end{array}$ & $\begin{array}{l}\text { Muro de sillares de caliza de } 3 \mathrm{~m} \\
\text { de espesor }\end{array}$ \\
\hline 12 & Plaza del Cabildo & Corzo (1997) & $\begin{array}{l}\text { Estructura de opus } \\
\text { caementicum }\end{array}$ \\
\hline 13 & $\begin{array}{l}\text { Portada de la Montería del } \\
\text { Alcázar }\end{array}$ & $\begin{array}{l}\text { Tabales (2006, 2010a } \\
\text { y 2010b) }\end{array}$ & $\begin{array}{l}\text { Estructura de sillares calizos } \\
\text { trabados con argamasa y cuñas } \\
\text { de ladrillo sobre emplecton } \\
\text { caementicio }\end{array}$ \\
\hline
\end{tabular}

Tabla 1. Estructuras vinculadas con registros de carácter poliorcético de Hispalis 
se puede sugerir que dicha ampliación tuviese lugar en su flanco septentrional.

El tercero se erigiría durante el siglo II d.C., como consecuencia del espectacular auge que experimentó la ciudad desde Claudio y sobre todo con los Antoninos. Sería contemporáneo por tanto de una importante transformación en la distribución de las necrópolis y de un ambicioso programa de reordenación urbanística. Este tiene sus hitos más espectaculares en los diversos complejos termales documentados en la Cuesta del Rosario, el Palacio Arzobispal y la calle Ababes, en las columnas de la calle Mármoles y en el castellum aquae de la Plaza de la Pescadería. Su trazado coincidiría grosso modo con el que la historiografía asigna a la Hispalis imperial

\section{BibliogRAFÍA}

Álvarez, J.M. (2007), "Consideraciones acerca del recinto amurallado emeritense", Murallas de ciudades romanas en el Occidente del Imperio. Lucvs Avgusti como paradigma, Lugo, 651-670.

Amores, F. (2005), "La cristianización de la ciudad de Sevilla en la tardoantigüedad", La catedral en la ciudad (I). Sevilla, de Astarté a San Isidoro, Sevilla, 140-160.

Amores, F. y González Acuña, D. (2004), Informe de la intervención arqueológica de urgencia en el solar del antiguo Mercado de la Encarnación (Sevilla). $V$ fase. Documento interno de la Delegación Provincial de la Consejería de Cultura de la Junta de Andalucía en Sevilla.

(2006a), "V Fase de intervención arqueológica en el Mercado de la Encarnación (Sevilla). Contextos tardoantiguos", Anuario Arqueológico de Andalucía/2003, III-2, Sevilla, 197-206.

(2006b), Memoria preliminar de la actividad arqueológica preventiva Proyecto de emergencia Plaza de la Encarnación (Sevilla). VI fase de intervención arqueológica, Documento interno de la Delegación Provincial de la Consejería de Cultura de la Junta de Andalucía en Sevilla.

Aparicio, L. (2001), "Intervención arqueológica de urgencia en el Paseo de la Victoria $n^{\circ} 49$ recayente a la c/ Tejón y Marín n ${ }^{\circ}$ 6, en el lienzo oeste de la muralla romana de Córdoba”, $A n$ uario Arqueológico de Andalucía/1999, III, $172-181$.
Beltrán Fortés, J., González Acuña, D. y Ordóñez, S. (2005), "Acerca del urbanismo de Hispalis. Estado de la cuestión y perspectivas", Mainake, XXVII, 61-88.

Beltrán Lloris, M. (1999), "Colonia Caesaravgvsta", Hispania. El legado de Roma, Zaragoza, 411415.

Bendala, M. (1999), "La paz augustea y la romanización”, Hispania. El legado de Roma, Zaragoza, 127-137.

Blanco, A. (1972), "La Sevilla Romana. Colonia Iulia Rómula Hispalis", Historia de urbanismo sevillano, Sevilla, 1-22.

(1979), Historia de Sevilla. La ciudad antigua (de la Prehistoria a los visigodos), Sevilla.

Blanco, A. y Corzo, R. (1976), "El urbanismo romano de la Bética", Symposion de ciudades augusteas, Zaragoza, 137-165.

Botella, D. (1995), "Intervención arqueológica de urgencia en plaza de Colón 8, Córdoba”, Anuario Arqueológico de Andalucía/1992, III, 235-243.

Brunt, P.A. (1971), Italian Manpower. 226 BC$14 A D$, Oxford.

Caballos, A., Marín, J. y Rodríguez Hidalgo, J.M. (1999), Itálica arqueológica, Sevilla.

Campos, J.M. (1989), "Análisis de la evolución espacial y urbana de Urso", Estudios sobre Urso. Colonia Genitiva Iulia, Sevilla, 99-111.

Campos, J.M., Gómez, F. y Pérez, J.A. (2006), Ilipla-Niebla. Evolución urbana y ocupación del territorio, Huelva.

Campos, J.M. y González, J. (1987), "Los foros de Hispalis Colonia Romvla”, Archivo Español de Arqueología 60, 123-158.

Campos, J.M. y Vidal, N. (1999), "El urbanismo de las ciudades romanas del territorio onubense: el caso de Iptucci (Tejada la Nueva)", II Congreso de Arqueología Peninsular. Arqueología romana y medieval, IV, Madrid, 229-236.

(2003), "Las ciudades hispano-romanas del territorio onubense. Estado de la cuestión", Revista d'Arqueologia de Ponent, 13, 41-81.

Carrasco, I., Murillo, J.F., Rodero, S., González, M.L. y Garriguet, J.A. (2003), "Informe-memoria de la I.A.U. en el Paseo de la Ribera (19992001). I. Sector de la Puerta del Puente", Anuario Arqueológico de Andalucía /2000, III-1, 283-298.

Carriazo, J. de M. (1974-1975), "Una zanja en el 
suelo de Sevilla”, Cuadernos de la Alhambra, 10-11, 91-97.

Collantes de Terán, F. (1977), Contribución al estudio de la topografía sevillana en la antigüedad y en la edad media, Sevilla.

Corzo, R. (1977a), Osuna de Pompeyo a César. Excavaciones en la muralla republicana, Sevilla.

(1977b), "Osuna. Excavaciones en la muralla republicana”, Noticiario Arqueológico Hispánico 5, $137-143$

(1979), “Arqueología de Osuna”, Archivo Hispalense 189, 117-137.

(1982), "Organización del territorio y evolución urbana en Itálica”, Excavaciones Arqueológicas en España, 121, 300-319.

(1991), "Las termas, la ciudad y el río de Sevilla en la antigüedad. Excavaciones en la calle Abades", Temas de Estética y Arte, V, 67-99.

(1997), "Sobre la topografía de Hispalis", Boletín de la Real Academia de Bellas Artes de Santa Isabel de Hungría, XXV, 193-211.

Engel, A. y Paris, P.(1906), "Une forteresse ibérique à Osuna (fouilles de 1903)”, Nouvelles Archives des Missions Scientifiques, XIII, 357-491.

Escacena, J.L. (2002), "Murallas fenicias para Tartessos. Un análisis darwinista”, Spal, 11, 69-106.

Escudero, J.M., Morena, J.A., Vallejo, A. y Ventura, A. (1999), "Las murallas de Córdoba (el proceso constructivo de los recintos desde la fundación romana hasta la Baja Edad Media)", Córdoba en la Historia: La construcción de la Urbe, Córdoba, 201-224.

Fernández Flores, A. y Rodríguez Azogue, A. (2003), "Intervención arqueológica en calle $\mathrm{Pla}$ centines 7 de Sevilla. Aportación al conocimiento de Hispalis, su delimitación, topografía y el carácter de las edificaciones del sector oeste de la ciudad romana”, Anuario Arqueológico de Andalucía/ 2000, III-2, 952-970.

Fernández Ochoa, C. y Morillo, A. (1991), "Fortificaciones urbanas de época bajoimperial en Hispania. Una aproximación crítica”, Cuadernos de Prehistoria y Arqueología de la Universidad Autónoma de Madrid, 18, 227-259.

(1992), "Fortificaciones urbanas de época bajoimperial en Hispania. Una aproximación crítica", Cuadernos de Prehistoria y Arqueología de la Universidad Autónoma de Madrid, 19, 319-360.

(2002), "Entre el prestigio y la defensa: la prob- lemática estratégico-defensiva de las murallas tardorromanas en Hispania”, Arqueología militar romana en Hispania, Gladius, Anejos 5, 577-589.

García-Dils, S. (2010), "El urbanismo de colonia Augusta Firma Astigi (Écija-Sevilla). Muralla, viario y red de saneamiento", Romvla, 9, 85116.

(2011), "Colonia Augusta Firma Astigi (Écija, Sevilla). La estructura urbana de una fundación romana en la Baetica", Colonias de César y Augusto en la Andalucía romana, Roma, 99128.

García García, M.A. (2007a), "El castellum aquae de Hispalis", La Catedral en la ciudad (III). Los Caños y los difuntos. Primer tomo, Sevilla, 5-20.

(2007b), "Aqua Hispalensis. Primer avance sobre la excavación de la cisterna romana de la Plaza de la Pescadería (Sevilla)", Romvla, 6, 125-142.

García y Bellido, A.(1955), "Las primeras invasiones moras (época romana) en España", Archivo del Instituto de Estudios Africanos, 33, 31-39.

Gómez, F. y Beltrán Pinzón, J.M. (2006), "Seguimiento arqueológico de apoyo a la restauración de las murallas de Niebla (Huelva): Fases de amurallamiento en el tramo Puerta de Sevilla-torre 26", Anuario Arqueológico de Andalucía / 2003, III-1, 640-652.

Gómez, F., Campos, J.M., Guerrero, O. y Benabat, Y. (2001), "Arqueología urbana en Niebla. Actuación de apoyo a la restauración de la puerta de Sevilla”, Anuario Arqueológico de Andalucía/1998,II, 112-120.

González Acuña, D. (2005), "Imágenes de Hispalis. De la visión mítica al conocimiento científico", La catedral en la ciudad (I). Sevilla, de Astarté a San Isidoro, Sevilla, 59-99.

(2011), Forma Vrbis Hispalensis. El urbanismo de la ciudad romana de Hispalis a través de los testimonios arqueológicos, Sevilla.

González Román, C. (1991), "Las colonias romanas de la Hispania meridional en sus aspectos socio-jurídicos”, La Bética en su problemática histórica, Granada, 87-110.

Gozalbes, E. (1979), "Incursiones de moros contra la Bética en el mundo antiguo", Jabega, 26, 5053.

Gros, P. (1992), "Moenia: aspects défensifs et aspects représentatifs des fortifications", Fortificationes antiquae, Amsterdam, 211-215. 
(1996), L'Architecture Romaine. 1. Les Monuments Publics, París.

Gros, P. y Torelli, M. (1988), Storia dell'urbanistica. Il mondo romano, Bari.

Grünhagen, W. (1982), "Cronología de la muralla de Munigua”, Homenaje a Sáenz de Buruaga, Madrid, 315-328.

Hauschild, T. (1994), "Murallas de Hispania en el contexto de las fortificaciones del área occidental del Imperio Romano”, La ciudad en el mundo romano, XIV Congreso Internacional de Arqueología Clásica, Tarragona, 223-232.

Hernández, J., Sancho, A. y Collantes de Terán, F. (1939), Catálogo Arqueológico y Artístico de la provincia de Sevilla, I, Sevilla.

(1955):,Catálogo Arqueológico y Artístico de la provincia de Sevilla. Tomo IV, Sevilla.

Hourcade, D. (2003), "Les murailles des villes romaines de l'Hispanie republicaine et augustéene: enceintes ou fortifications du territoire urbain?", Defensa y territorio en Hispania de los Scipiones a Augusto, León, 295-324.

Ibáñez, A. (1990), "Intervención Arqueológica de Urgencia en la Ronda de los Tejares 6 de Córdoba”, Anuario Arqueológico de Andalucía/1987, III, 176-181.

Izquierdo, R. (2007), "Fortissimum oppidum. Investigaciones en la muralla romana de Alcalá del Río", Ilipa antiqua. De la Prehistoria a la época romana, Actas del I Congreso de Historia de Alcalá del Río, Alcalá del Río, 193-209.

(2009), “Intervención arqueológica preventiva en la calle Antonio Reverte $\mathrm{n}^{\mathrm{0}} 80$ de Alcalá del Río (Sevilla)", Anuario Arqueológico de Andalucía/2004.1, 3048-3059.

Jiménez Martín, A. (1977), “Arquitectura romana de la Bética I. Introducción al estudio de las fortificaciones", Segovia y la Arqueología Romana, Barcelona, 223-238.

(1981), "Análisis formal y desarrollo histórico de la Sevilla medieval”, La arquitectura de nuestra ciudad, Sevilla, 11-29.

(1985), "Arquitectura de la Sevilla preislámica", Breve historia de la arquitectura en Sevilla, Sevilla, 7-14.

(1989), La puerta de Sevilla en Carmona, Sevilla.

(2002), "Síntesis a modo de epílogo", Magna Hispalensis (I). Recuperación de la aljama almohade, Granada, 473-481.

Jiménez Salvador, J.L. (1999), "Urbanismo y obras públicas”, Hispania. El legado de Roma,
Zaragoza, 143-149.

Jiménez Sancho, A. (2002), "Excavación en C/ Abades 41-43 (Sevilla); del siglo III a.C. al siglo IV”, Romvla, 1, 125-150.

Keppie, L. (1983), Colonisation and veteran settlement in Italy. 47-14 B.C, London.

Lander, J. (1984), Roman Stone Fortifications. Variation and Change from the First Century A.D. to the Fourth, Oxford.

Larrey, E. y Verdugo, J. (1995), "Intervención arqueológica de urgencia en el tercer patio del Palacio Arzobispal de Sevilla. El corte de la estancia 10", Anuario Arqueológico de Andalucía/1992, III, 553-574.

León Muñoz, A., León Pastor, E. y Murillo, J.F. (2008), "El Guadalquivir y las fortificaciones urbanas de Córdoba", Las fortificaciones y el mar, Actas $4^{\mathrm{O}}$ Congreso Internacional sobre Fortificaciones, Alcalá de Guadaira, 261-290.

López, N. (2002), "Nuevos datos sobre la muralla este de Córdoba", Arte, Arqueología e Historia, 9, 103-108.

Mann, J.C. (1983), Legionary recruitment and veteran settlement during the Principate, London.

Márquez, C. (2003), "Los restos romanos de la calle Mármoles en Sevilla", Homenaje a Pierre Gros, 2, Romvla, 127-148.

Martín, M. (1993), "La ciudad hispanorromana en el valle del Ebro", La ciudad hispanorromana, Barcelona, 108-127.

Mateos, P. (2004), “Topografía y evolución urbana”, Las capitales provinciales de Hispania 2. Mérida. Colonia Augusta Emerita, Roma, 27-39.

Melchor, E. (1994), El mecenazgo cívico en la Bética. La contribución de los evergetas al desarrollo de la vida municipal, Córdoba.

Molina, J.A. (2005), "Nuevos datos sobre el lienzo septentrional de la muralla de Córdoba", Romvla, 4, 99-114.

(2009), "Actividad arqueológica preventiva en Ronda de los Tejares, 11 (Córdoba)", Anuario Arqueológico de Andalucía 2004.1 Córdoba, 628-636.

Molina, J.A. y Valdivieso, A. (2007), “Aportaciones sobre la evolución de las murallas de la Córdoba romana a partir de los datos arqueológicos", Romvla, 6, 29-50.

Montoto, S. (1981), Parroquias de Sevilla, Sevilla. Murillo, J.F. (2004), “Topografía y evolución ur- 
bana”, Las capitales provinciales de Hispania 1. Córdoba. Colonia Patricia Corduba, Roma, 39-54.

(2006), "Fases de desarrollo urbanístico y modelos monumentales en las ciudades hispanas I. Desde la fundación de Gadir a César", El concepto de lo provincial en el mundo antiguo, I, Homenaje a la profesora Pilar León, Córdoba, 327-390.

Murillo, J.F. y Jiménez Salvador, J.L. (2002), "Nuevas evidencias sobre la fundación de Corduba y su primera imagen urbana", Valencia y las primeras ciudades romanas de Hispania, Valencia, 183-193.

Ojeda, R. (1993), "Un edificio islámico en el solar de la Casa de Mañara”, Casa-Palacio de Miguel de Mañara. Restauración, Sevilla, 120-138.

(1995), "Un edificio almohade bajo la Casa de Miguel de Mañara”, El último siglo de la Sevilla islámica (1147-1248), Salamanca, 203-216.

(2001), "Nuevos datos sobre la Puerta de Córdoba en época romana", Carmona romana, Actas del II congreso de historia de Carmona, Carmona, 159-187.

Ojeda, R. y Tabales, M.A. (1994), "Estudio diacrónico de la ocupación del edificio islámico bajo el Palacio de Mañara (Sevilla): tres usos, tres culturas (siglos XII-XV)", IV Congreso de Arqueología Medieval Española, II, Alicante, $137-145$.

(1996), "La investigación arqueológica en Bienes Inmuebles. Metodología aplicada en la Puerta de Córdoba de Carmona”, Boletín del Instituto Andaluz del Patrimonio Histórico, 15, 41-52.

Oliva, P. (2008), Vigilancia arqueológica de movimientos de tierra en calle Orfila, Sevilla, Documento interno de la Delegación Provincial de la Consejería de Cultura de la Junta de Andalucía en Sevilla.

Ordóñez, S. (1998), Los primeros pasos de la Sevilla romana (siglo I a.C.-siglo I d.C.), Sevilla.

(2002), "Sevilla romana", Edades de Sevilla. Hispalis, Isbiliya, Sevilla, Sevilla, 11-38.

(2003), "El puerto romano de Hispalis", Puertos Fluviales Antiguos: Ciudad, Desarrollo e Infraestructuras, IV Jornadas de Arqueología Subacuática, Valencia, 59-79.

(2005), "Hispalis. Perfil histórico", La catedral en la ciudad (I). Sevilla, de Astarté a San Isidoro, Sevilla, 100-139.
Ordóñez, S. y González Acuña, D. (2009), "Colonia Romula Hispalis: Nuevas perspectivas a partir de los recientes hallazgos arqueológicos”, Andalucía romana y visigoda. Ordenación y vertebración del territorio, Roma, 65-98.

(2011), "Colonia Romula Hispalis. Líneas esenciales de su dinámica histórica y arqueológica”, Colonias de César y Augusto en la Andalucía romana, Roma, 47-97.

Pachón, J.A. (2011), "De la Urso tardo-republicana a la Colonia Genetiva Iulia. Un análisis desde la historiografía y la arqueología”, Colonias de César y Augusto en la Andalucía romana, Roma, 187-222.

Pachón, J.A. y Ruiz Cecilia, J.I. (2005), "La muralla Engel/Paris y la necrópolis protohistórica de Osuna”, Florentia Iliberritana, 16, 383-423.

Pellicer, M. (1982), "Excavaciones en Itálica (19781979). Muralla, cloacas y cisterna”, Excavaciones Arqueológicas en España, 121, 206-224.

Pozo, F., Hunt, M. y Mercado, L. (2006), “Actuaciones arqueológicas en la construcción de la Línea 1 de Metro de Sevilla", El patrimonio arqueológico y paleontológico en las obras de ampliación del Metro de Madrid (20032007), Madrid, 205-215.

Prados, E. (2007), "Intervención arqueológica en el sector este de Alcalá del Río. La muralla de la calle Pasaje Real 2-4", Ilipa antiqua. De la Prehistoria a la época romana, Actas del I Congreso de Historia de Alcalá del Río, Alcalá del Río, 267-282.

Rebuffat, R. (1986), "Les fortifications urbaines romaines", La fortification dans l'histoire $d u$ monde grec, París, 345-361.

Rodero, S., González Virseda, M.L., Garriguet, J.A. y Murillo, J.F. (2003), "Informe-memoria de la I.A.U. en el Paseo de la Ribera (1999-2001). II. Sondeos arqueológicos efectuados en el Paseo de la Ribera con motivo de la instalación del colector marginal del río (Plan Urban-Ribera)", Anuario Arqueológico de Andalucía/ 2000, III-1, 251-267.

Rodríguez Hidalgo, J.M. (1997), "La nueva imagen de la Itálica de Adriano", Italica MMCC, Actas de las Jornadas del 2200 Aniversario de la Fundación de Itálica, Sevilla, 87-114.

(1998), Informe previo de la tercera fase de la intervención arqueológica en el solar $n^{\circ} 41$ de la calle Francos de Sevilla, Documento 
interno de la Delegación Provincial de la Consejería de Cultura de la Junta de Andalucía en Sevilla.

Rodríguez Hidalgo, J.M, Keay, S. K., Jordan, D., Greighton, J. y Rodá, I. (1999), "La Itálica de Adriano. Resultados de las prospecciones de 1991 y 1993”, Archivo Español de Arqueología, 72, 73-97.

Roldán, L. (1993), Técnicas constructivas romanas en Itálica (Santiponce, Sevilla), Madrid.

Romo, A.S. (1999), "El sondeo estratigráfico de la Plaza Virgen de los Reyes (Sevilla). El registro deposicional”, Anuario Arqueológico de Andalucía/1994, III, 422-432.

Romo, A.S., Vargas Jiménez, J.M. y Rodríguez Hidalgo, J.M. (2002), "El recinto fortificado de Ilipa Magna (Alcalá del Río)”, Castillos de España, 125, 35-38.

Ruiz Nieto, E. (2002), "Nuevo seguimiento del recinto murado de Colonia Patricia Corduba (I.A.U. en Paseo de la Victoria, 17)", Arte, Arqueología e Historia, 9, 95-102.

(2003), "Intervención Arqueológica de Urgencia en el Paseo de la Victoria, 17", Anuario Arqueológico de Andalucía/2000, III-1, 475-482.

Sáez, P., Ordóñez, S. y García-Dils, S. (2005), "El urbanismo de la Colonia Augusta Firma Astigi: nuevas perspectivas", Mainake, XXVII, 89-112.

Sáez, P., Ordóñez, S., García Vargas, E. y GarcíaDils, S. (2004), Écija. 1: La ciudad: carta arqueológica municipal, Sevilla.

Salas, J. (2002), Imagen historiográfica de la antigua Vrso (Osuna, Sevilla), Sevilla.

Santos, N. (1980), "Las invasiones de los moros en la Bética del siglo II d. N. E.”, Gades, 5, 51-62.

Schattner, T.G. (2003), Munigua. Cuarenta Años de Investigaciones, Sevilla.

(2005), "La Puerta de Sevilla en Carmona y otras puertas romanas en la Península Ibérica”, Romvla 4, 67-98.

Tabales, M.A. (2002a), "Investigaciones en la primitiva puerta del Alcázar de Sevilla", Anuario Arqueológico de Andalucía / 1999, II, 95-211.

(2002b), La primitiva puerta del Alcázar de Sevilla. Memoria arqueológica, Madrid.

(2002c), El Alcázar de Sevilla. Primeros estudios sobre estratigrafía y evolución constructiva, Sevilla.

(2006), "Investigaciones arqueológicas en la portada de la Montería del Alcázar de Sevilla", Apuntes del Alcázar de Sevilla, 7, 6-39. (2010a), "Alcázar de Sevilla. Campaña 2005. Investigaciones arqueológicas en la portada de la Montería”, Anuario Arqueológico de Andalucía/2005. Sevilla, 2716-2741.

(2010b), El Alcázar de Sevilla. Reflexiones sobre su origen y transformación durante la Edad Media. Memoria de Investigación Arqueológica 2000-2005, Sevilla.

(2010c), Informe proyecto general de investigación Análisis Arqueológico del Alcázar de Sevilla II Patio de Banderas. Fase I noviembre 2010, Documento interno de la Delegación Provincial de la Consejería de Cultura de la Junta de Andalucía en Sevilla.

Taylor, R. (2010), "Nuevos datos sobre la muralla romana de Alcalá del Río: intervención arqueológica en calle Sol 50", Anuario Arqueológico de Andalucía/ 2005. Sevilla, 4012-4022.

Thouvenot, R. (1940), Essai sur la province romaine de Bétique, París.

Valdivieso, A. (2010), "Actividad Arqueológica Preventiva en la Avda. Ronda de los Tejares nº 9 de Córdoba”, Anuario Arqueológico de Andalucía/2006. Córdoba, 752-764.

Valor, M. (1991), La arquitectura militar y palatina en la Sevilla musulmana, Sevilla.

Vaquerizo, D., Murillo, J.F. y Garriguet, J.A. (2011), "Novedades de arqueología en Corduba, Colonia Patricia”, Colonias de César y Augusto en la Andalucía romana, Roma, 9-46.

Vargas Lorenzo, C. (2010), "Estudio cronotipológico y constructivo", Informe proyecto general de investigación Análisis Arqueológico del Alcázar de Sevilla II Patio de Banderas. Fase I noviembre 2010, Documento interno de la Delegación Provincial de la Consejería de Cultura de la Junta de Andalucía en Sevilla.

Vázquez, J. (2010), "Nuevos datos arqueológicos para el conocimiento de la topografía romana y medieval de Sevilla: los niveles islámicos y romanos de la calle Alemanes $\mathrm{n}^{\mathrm{O}} 25$ de Sevilla”, Anuario Arqueológico de Andalucía/2005. Sevilla, 3165-3176.

Ventura, A., Bermúdez, J.M., León, P., López, I.M., Márquez, C. y Ventura, J.J. (1996), “Análisis arqueológico de la Córdoba romana: Resultados e hipótesis de la investigación”, Colonia Patricia Corduba. Una reflexión arqueológica, Córdoba, 87-118.

Vera Reina, M.(1987), “Aportación al conocimiento de la Sevilla antigua. Revisión de la excavación 
de Cuesta del Rosario", Archivo Hispalense, $215,37-60$.

Vidal, N. (2007), Análisis arqueológico de la romanización del territorio onubense, Huelva.

Villa, C. (2010), "Control arqueológico de los movimientos de tierra en obras de renovación de la red de abastecimiento y saneamiento en tramo c/ Maestra Aurora Martel-Pasaje Real de Alcalá del Río", Anuario Arqueológico de Andalucía/2006. Sevilla, 4129-4142

Vioque, R., Vera Rodríguez, I. M $\mathrm{a}^{\mathrm{a}}$ y López, N. (1987), Apuntes sobre el origen y evolución morfológica de las plazas del casco histórico de Sevilla, Sevilla. 